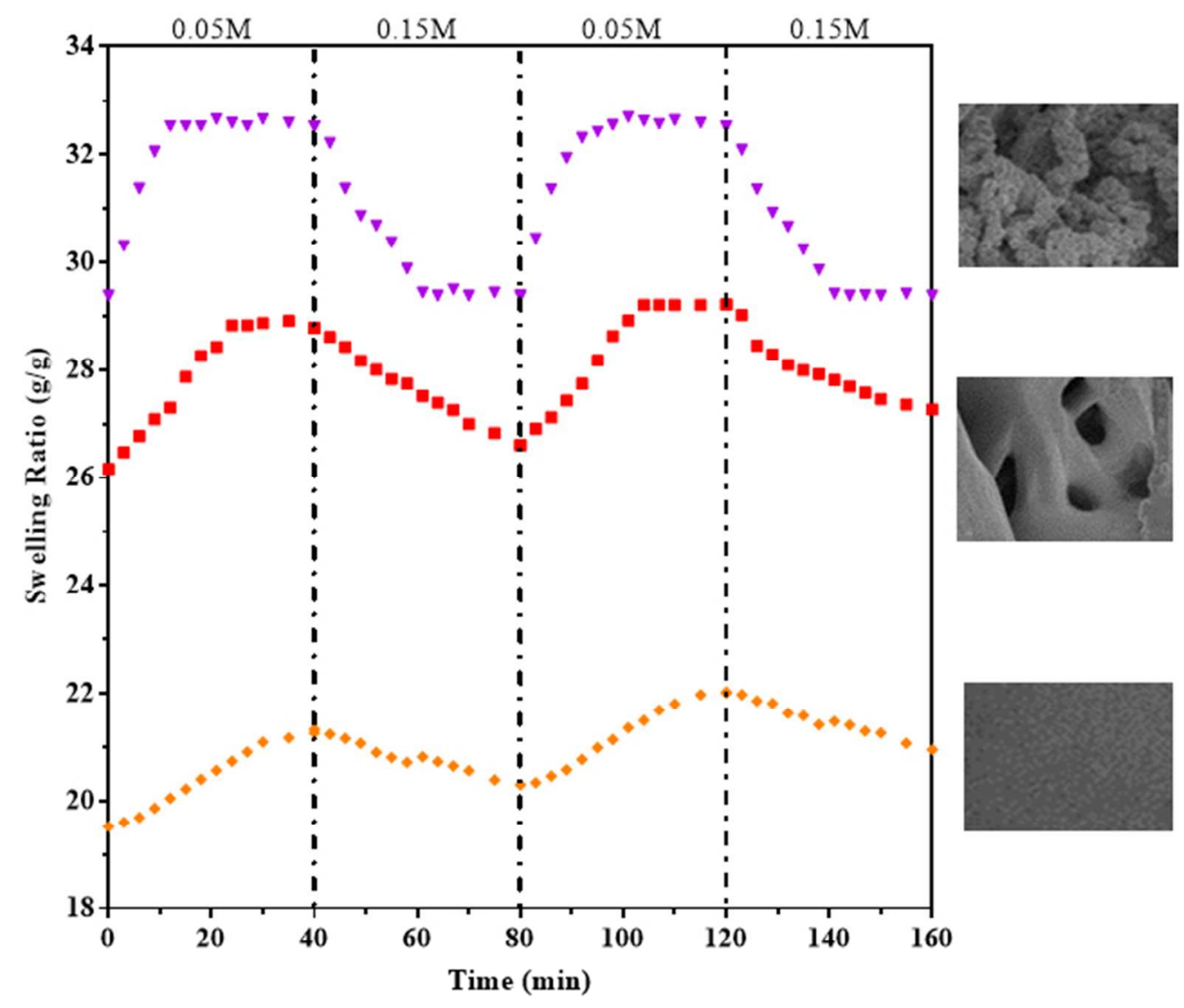

$170 \times 170 \mathrm{~mm}(96 \times 96$ DPI)

This is the author manuscript accepted for publication and has undergone full peer review but has not been through the copyediting, typesetting, pagination and proofreading process, which may lead to differences between this version and the Version record. Please cite this article as doi:10.1002/ app.43515. 


\section{Rapid swelling and deswelling of semi-interpenetrating network poly(acrylic acid)/poly(aspartic acid) hydrogel prepared by freezing polymerization}

Swee Lu Lim ${ }^{a}$, Willie Ngee Hon Tang ${ }^{b}$, Chien Wei Ooi ${ }^{a, c}$, Eng-Seng Chan ${ }^{a, c}$, Beng Ti Tey ${ }^{a, c^{*}}$

a Chemical Engineering Discipline, School of Engineering, Monash University Malaysia, Jalan Lagoon Selatan, Bandar Sunway 47500, Selangor, Malaysia.

${ }^{b}$ Department of Chemical and Biomolecular Engineering, The University of Melbourne, Victoria 3010, Australia.

${ }^{c}$ Advanced Engineering Platform, Monash University Malaysia, Jalan Lagoon Selatan, Bandar Sunway 47500, Selangor, Malaysia.

Corresponding author: Beng Ti Tey (tey.beng.ti@monash.edu)

\section{ABSTRACT}

Hydrogels with semi-interpenetrating network composed of poly(acrylic acid) (PAAc) and poly(aspartic acid) (PASP) has a great potential for pharmaceutical and biomedical applications. This study aimed to synthesize semi-interpenetrating PAAc/PASP hydrogel with the improved swellingdeswelling properties via two-step polymerization, wherein the first step of polymerization was performed at $37^{\circ} \mathrm{C}$ for 15 minutes, followed by the freezing polymerization $\left(-20^{\circ} \mathrm{C}\right)$ for 24 hours. The synthesized hydrogels were characterized by using field emission scanning electron microscopy, Fourier transform infrared spectroscopy, and thermal gravimetric analysis. The swelling and deswelling behaviors of the hydrogels in response to ionic strength of the buffer solution were investigated. The Schott's swelling kinetic model was employed to elucidate the swelling behaviour of hydrogel. The swelling and deswelling rates of the hydrogels prepared via freezing polymerization were faster than that of the hydrogels prepared via conventional polymerization. This was attributed to the large mean pore size of freeze-polymerized hydrogels. The PAAc/PASP hydrogels undergone the freezing polymerization have a better swelling-deswelling characteristic than the PAAc hydrogels.

John Wiley \& Sons, Inc.

This article is protected by copyright. All rights reserved. 


\section{INTRODUCTION}

Hydrogel, a three-dimensional network formed by the covalently cross-linked hydrophilic polymer, can accommodate a large amount of water or biological fluids while maintaining its spatial network structure $^{1}$. A stimuli-responsive hydrogel responds to the changes in environmental condition (e.g., $\mathrm{pH}$, ionic strength, temperature, light, biomolecules, electric and magnetic field) by undergoing abrupt changes in its volume $\mathrm{e}^{2-7}$. Ionic-strength-responsive hydrogels hold great potential in applications such (a)

as biosensor ${ }^{8}$ and delivery systems for gene $^{9}$ and proteins ${ }^{10}$ because they mimics the natural environment for biomolecules and ensure the stability of biomolecules residing in its internal structure $^{11}$. Ionic-strength-responsive hydrogel was successfully employed as a glucose sensor ${ }^{12}$ and in a reversible enzyme binding system ${ }^{11}$. For example, the glucose in human body can trigger the swelling of polyacrylamide hydrogels embedded with glucose oxidase (GOD) due to the increasing concentration of anionic GOD flavin adenine dinucleotide (FAD) prosthetic group ${ }^{12-14}$. Interpenetrating polymer networks (IPN) are defined as 'a combination of two or more polymers in network form that are synthesized in juxtaposition, ${ }^{15}$. They can also be described as the cross-linked polymer networks held together by permanent entanglements. Semi-interpenetrating (semi-IPN) hydrogel is made of two types of polymers cross-linked during polymerization. The semi-IPN hydrogel retains the intrinsic properties of both polymers, and, sometimes, it has the enhanced properties in comparison to the hydrogel made of the discrete polymer ${ }^{16}$. Poly(acrylic acid) (PAAc) hydrogel exhibits swelling and deswelling behaviours in response to a variation in $\mathrm{pH}$ or ionic strength $^{17-19}$. However, PAAc hydrogel requires hours to weeks to achieve an equilibrium state ${ }^{20}$ due

to the low porosity and the small-size pores in the hydrogel. On the other hand, poly(aspartic acid) (PASP) is an amino-acid-based polymer that possesses the desirable characteristics like biodegradability, biocompatibility and toxicological suitability ${ }^{16,21}$. Therefore, the incorporation of PASP into PAAc hydrogel yields a type of biodegradable semi-IPN hydrogel featuring an improved sensitivity towards $\mathrm{pH}$ or ionic strength ${ }^{1,16}$. The semi-IPN PAAc/PASP hydrogel can be synthesized 
by diffusing AAc monomers into the PASP matrix before the polymerization step. The PAAc network formed in the presence of linear PASP polymers behaves like a reptile chain entangling with the network chains ${ }^{15}$. Hence, most of the PASP polymers in the semi-IPN hydrogel would be retained as they were entangled and concatenated with the PAAc network ${ }^{15}$. PASP polymers cannot be separated from the hydrogel network without breaking the cross-linking bond between monomers ${ }^{15}$.

The widespread application of ionic-strength-responsive hydrogels in bio-related fields, for example drug delivery and biosensor, demands a deeper understanding on the swelling properties of semi-IPN PAAc/PASP hydrogel in physiological fluid. The responsivity of hydrogel could be improved by increasing its porosity through a step of freezing polymerization during the synthesis process. The high surface-to-volume ratio in hydrogel allows a more rapid diffusion of solute and solvent into the hydrogel, leading to a quicker change in the hydrogel's volume. The freezing polymerization is generally conducted in a moderately frozen medium. A temperature-responsive poly $(\mathrm{N}-$ isopropylacrylamide-co-acrylic acid) $\quad[\mathrm{P}(\mathrm{NIPA}-\mathrm{co}-\mathrm{AA})]$ hydrogel prepared via freezing polymerization demonstrated an enhanced temperature responsiveness over the hydrogel synthesized via conventional polymerization ${ }^{22}$. Besides, a hydrogel made of poly(N,N-diethylacrylamide-coacrylic acid) $[\mathrm{P}(\mathrm{DEA}-\mathrm{co}-\mathrm{AA})]$ can be prepared by using two-stage polymerization in which the first stage of the polymerization was carried out at a relatively high temperature for $15 \mathrm{~min}$, followed by a freezing polymerization at $-30^{\circ} \mathrm{C}(12 \text { hours })^{23}$. It was found that the higher the temperature used in the first stage of polymerization, the better the responsiveness of the hydrogels to stimuli such as temperature and $\mathrm{pH}^{23}$. Thus, freezing polymerization has been viewed as a promising technique to produce polyelectrolyte hydrogels.

In view of the potential use of semi-IPN PAAc/PASP hydrogel in biomedical field as bio-sensing material, polymeric drug carriers/adsorbent, it is necessary to investigate the swelling kinetics of semi-IPN PAAc/PASP hydrogel in buffer saline solutions prepared at different ionic strength. Here we report a method to synthesize the semi-IPN hydrogel with expanded network structure by the two-

John Wiley \& Sons, Inc. 
step polymerization, wherein the initial polymerization was carried out at $37^{\circ} \mathrm{C}$ for $15 \mathrm{~min}$, followed by freezing polymerization at $-20^{\circ} \mathrm{C}$ for 24 hours. The swelling of the semi-IPN PAAc/PASP hydrogel is mainly ascribed to the functional groups of ionic carboxylate and non-ionic carboxamide. The ionic groups are more solvated compared to the non-ionic groups in the aqueous medium. The super absorbency might result from an expanded network of hydrogel, which is attributed by the strong electrostatic repulsion force from PAAc and PASP carboxylate anions $\left(-\mathrm{COO}^{-}\right)$. The effect of r

freezing polymerization on the resulted semi-IPN hydrogels was evaluated. The responsivity of semiIPN hydrogels towards the ionic strength of phosphate buffer saline (PBS) solution was investigated by analyzing the swelling kinetics of the hydrogels. This smart and responsive hydrogel would be a promising material for building biological systems applied in the fields of biomedical, biosensor and pharmaceutical.

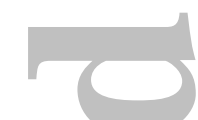

\section{EXPERIMENTAL}

\subsection{Materials}

PASP (molecular weight of 2000-11000 g/mol), acrylic acid (AAc), ammonium persulfate (APS), $N, N^{\prime}$-methylenebisacrylamide (MBA) and $N, N, N^{\prime}, N^{\prime}$-tetramethylethylenediamine(TEMED) were purchased from Sigma-Aldrich, USA. All of the chemicals were of analytical grade and were used without further purification.

\subsection{Synthesis of hydrogels}

The hydrogels were synthesized by using free-radical polymerization (see Figure 1). According to the composition of hydrogels shown in Table 1, the AAc, PASP, APS, MBA and TEMED were mixed into PBS solution (700 $\mu \mathrm{L} ; 0.02 \mathrm{M} ; \mathrm{pH} 7.4)$ under stirring condition. The APS functioned as an 
initiator, while the MBA and TEMED were used as the cross-linker and accelerator, respectively. The reaction glass vials were then incubated at $37^{\circ} \mathrm{C}$ for 15 min to begin the first-step polymerization ${ }^{23,24}$. The conversion of the monomer in the first-step polymerization was consistent for all the hydrogels, since the synthesis condition (concentrations of monomer and initiators, reaction time, and temperature) was kept constant. Next, the second-step polymerization was initiated by transferring the reactants immediately to a $-20^{\circ} \mathrm{C}$ reactor (freeze polymerization) or by incubating the reactants at $25^{\circ} \mathrm{C}$. The second-step polymerization lasted for 24 hours. The synthesized hydrogels were immersed in PBS solution (0.02M; pH 7.4) for five consecutive days, with the PBS solution being replaced routinely to remove the unreacted AAc, PASP, and other soluble chemicals from the hydrogels. The thoroughly washed hydrogels was further incubated in PBS solution for 7 days. No sign of leakage was observed for the synthesized semi-IPN PAAc/PASP hydrogel (see Supporting Information).

Lastly, the hydrogels were cut into discs with a thickness of 3-4 mm and a diameter of $1 \mathrm{~cm}$.

\subsection{Characterization of PAAc and semi-IPN PAAc/PASP hydrogels}

\subsubsection{Scanning electron microscopy}

Interior morphology of the hydrogels was studied by using field emission scanning electron microscopy (FE-SEM) (Hitachi SU8010, Germany). The hydrogels were equilibrated in PBS solution (0.05M; $\mathrm{pH} 7.4)$ before subjected to freeze-drying at $-109^{\circ} \mathrm{C}$ under vacuum condition. Prior to the viewing under FE-SEM, the dried hydrogels were sputter-coated with platinum.

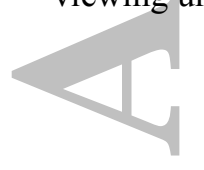

\subsubsection{Fourier transform infrared (FT-IR) spectroscopy}


The hydrogels were dried until a constant weight was obtained. The dried hydrogels were then ground into fine powder, which was then compressed into a disc form. The pelleted samples were analyzed by using a FT-IR spectrometer (Thermoscientific Nicolet iS10, USA) in the region of 4000-550 $\mathrm{cm}^{-1}$.

\subsubsection{Thermal gravimetric analysis (TGA)}

TGAs of dried hydrogels were conducted by a thermogravimetric analyzer (model Q50, TA Instruments, USA). The thermograms of hydrogels were recorded at a heating rate of $10^{\circ} \mathrm{C} / \mathrm{min}$ over the temperature range of $10-600^{\circ} \mathrm{C}$. During the analysis, nitrogen gas was purged at a flow rate of 20 $\mathrm{mL} / \mathrm{min}^{21} . t_{1 / 2}$ was calculated as the temperature at which half the composition has been degraded within $^{25}$.

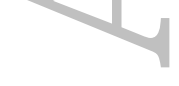

\subsection{Equilibrium swelling ratio $\left(S_{\text {eq }}\right)$ of hydrogel}

$\mathrm{S}_{\mathrm{eq}}$ of hydrogel was investigated by allowing the hydrogel to swell in PBS solution (0.05M; pH 7.4) for 24 hours at room temperature. The wet hydrogel was then weighed. The $\mathrm{S}_{\mathrm{eq}}(\mathrm{g} / \mathrm{g})$ was calculated by using equation $(1)^{1}$ :

$$
\mathrm{S}_{\mathrm{eq}}=\frac{\mathrm{W}_{\mathrm{eq}}-\mathrm{W}_{\mathrm{d}}}{\mathrm{W}_{\mathrm{d}}}
$$

, where $\mathrm{W}_{\text {eq }}$ is the weight ( $\mathrm{g}$ ) of equilibrium-swollen hydrogel, and $\mathrm{W}_{\mathrm{d}}$ is the weight $(\mathrm{g})$ of the dried hydrogel.

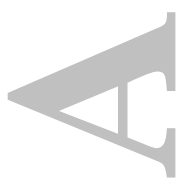

\subsection{Swelling behavior of hydrogel}

Swelling behavior of the hydrogel in the simulated physiological fluids was investigated by using PBS solutions $(\mathrm{pH} 7.4)$ prepared at different ionic strength $(0.05 \mathrm{M}$ and $0.15 \mathrm{M})$. The classical gravimetric method was employed to determine the swelling characteristic of the hydrogel. Briefly,

John Wiley \& Sons, Inc. 
the hydrogel was first pre-equilibrated in $0.15 \mathrm{M}$ PBS solution. Subsequently, the hydrogel was transferred into $0.05 \mathrm{M}$ PBS solution and was incubated at room temperature until it reached the equilibrium state. After blotting excess water on hydrogel's surface, the weight of the hydrogel was measured. Each measurement of sample weight was repeated thrice.

The swelling ratio of hydrogel at time interval $t\left(\mathrm{~S}_{\mathrm{t}}\right)$ was determined by using the following equation

$$
\text { (2) }{ }^{1} \text { : }
$$

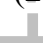

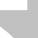

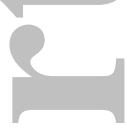

$$
\mathrm{S}_{\mathrm{t}}(\mathrm{g} / \mathrm{g})=\frac{\mathrm{W}_{\mathrm{t}}-\mathrm{W}_{\mathrm{d}}}{\mathrm{W}_{\mathrm{d}}}
$$

where $\mathrm{W}_{\mathrm{t}}$ is the weight $(\mathrm{g})$ of swollen hydrogel at time interval $t$.

\subsubsection{Swelling kinetics of hydrogel}

$\mathrm{S}_{\mathrm{t}}$ was fitted into the following Schott's second-order swelling kinetics model (3) ${ }^{26}$ in order to obtain the swelling kinetic parameters of the hydrogel ${ }^{1,27}$ :

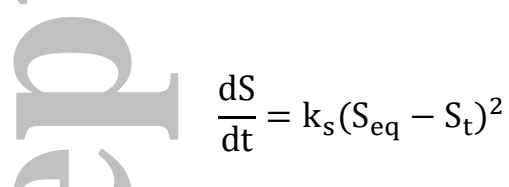

, where $\mathrm{k}_{\mathrm{s}}$ is the rate constant (g gel/g water.min).

By applying the initial conditions, i.e., $\mathrm{S}_{\mathrm{t}}=0$ at $t=0$, and $\mathrm{S}_{\mathrm{t}}=\mathrm{S}_{\mathrm{t}}$ at $t=\mathrm{t}$, the second-order kinetics equation could be integrated into the following equation (4) ${ }^{1}$ :

$$
\frac{\mathrm{t}}{\mathrm{S}_{\mathrm{t}}}=\frac{1}{\mathrm{r}_{0}}+\frac{1}{\mathrm{~S}_{\mathrm{eq}}} \mathrm{t}
$$

, where the initial swelling rate, $\mathrm{r}_{0}$, (g water/g gel.min) is equivalent to $1 / \mathrm{k}_{\mathrm{s}} \mathrm{S}_{\mathrm{eq}}{ }^{227-29}$.

\subsection{Deswelling kinetics of hydrogel}

John Wiley \& Sons, Inc. 
The pre-equilibrated (in PBS solution at $0.05 \mathrm{M}$ and $\mathrm{pH}$ 7.4) hydrogel was transferred to PBS solution (0.15M; $\mathrm{pH} 7.4)$. The wet weight of hydrogel at different time $t\left(\mathrm{~W}_{\mathrm{t}}\right)$ was measured after the removal of excess water from hydrogel surface. Water retention percentage (WR, \%) of the hydrogel was calculated by using equation $(5)^{21}$ :

$$
W R(\%)=\frac{W_{t}-W_{d}}{W_{\text {eq }}-W_{d}} \times 100 \%
$$

\subsection{Oscillating swelling/deswelling kinetics of the hydrogels}

The hydrogels were pre-equilibrated in PBS solution $(0.15 \mathrm{M} ; \mathrm{pH} 7.4)$ at room temperature for 24 hours. The oscillatory swelling/deswelling of the hydrogels in PBS (pH 7.4) solutions at the alternate ionic strength of $0.05 \mathrm{M}$ and $0.15 \mathrm{M}$ was examined. In brief, after incubating the hydrogel in $0.05 \mathrm{M}$ PBS solution for $40 \mathrm{~min}$, the swollen hydrogel was transferred to $0.15 \mathrm{M}$ PBS solution for the next 40 min incubation. This 80 -min swelling-deswelling cycle was repeated twice and the wet weight of the hydrogel was recorded ${ }^{21}$. The $\mathrm{S}_{\mathrm{t}}$ was calculated using equation (2).

\section{RESULTS AND DISCUSSION}

\subsection{FE-SEM analysis}

The microstructure of the hydrogels can be related to the diffusion pattern of water in the hydrogels.

The micrographs showing the interior morphology of the freeze-dried hydrogels are presented in Figures 2a-e. The surfaces of PAAc hydrogels (Figures 2a and $2 \mathrm{~b}$ ) were smoother than that of IPN hydrogels (Figures $2 \mathrm{c}$ and $2 \mathrm{~d}$ ). The rough and porous surfaces of IPN hydrogel could be attributed to the presence of PASP in its structure. The PASP contains the hydrophilic groups (-CONH and $\mathrm{COOH})$ that will be ionized $\left(-\mathrm{COO}^{-}\right)$during the polymerization process. The repulsive forces among 
the PASP's carboxylate anions ${ }^{30}$ resulted in the formation of a porous gel and rendered a highly expanded network in IPN hydrogel structure. The presence of void or inhomogeneity in the hydrogel was caused by the micro-phase separation between AAc monomers and PASP polymer chains, thereby creating the domain difference followed by the crosslinking to form the polymer network. The hydrogel network would uphold its spatial arrangement and conformation history of its porous structure $^{32-34}$. Hence, an expanded network structure with a porous molecular conformation was retained even after the hydrogel had been freeze-dried. The micrographs of hydrogels affirmed the porous structure resulted from the expanded network of hydrogel.

As shown in Figures $2 b$ and $2 d$, the microstructures of hydrogels formed via the second-step freezing polymerization (i.e., PAA 37-F20 and IPN 37-F20) were more open/loose and they contained larger pores in comparison to their respective types formed at $25^{\circ} \mathrm{C}$ in the second polymerization step (see Figures $2 \mathrm{a}$ and $2 \mathrm{c}$ ). The freezing polymerization facilitated the expansion of hydrogel network, giving the large-pore microstructure of the hydrogel. This phenomenon might be attributed to the formation of crystallized water molecules, which acted as the pore-forming agent in hydrogel structure, during the freezing polymerization ${ }^{23,35}$. On the contrary, the cross-sectional views of PAA $37-25$ and SC showed the non-porous surfaces (Figures $2 \mathrm{a}$ and 2e). The micro-size particles were found in the IPN 37-F20 hydrogel (Figure 2d). These particles were believed to be the small-size gels synthesized during the two-step polymerization ${ }^{23}$.

\subsection{FT-IR spectrum of PAA/PASP semi-IPN hydrogel}

The chemical composition of PAA/PASP semi-IPN hydrogel was studied by the FTIR analysis. The FTIR spectra of PAAc, PASP and semi-IPN PAAc/PASP hydrogel are shown in Figure 3. PASP contained carboxylic acid group $(-\mathrm{COOH})$, as evidenced by the peak at $1399 \mathrm{~cm}^{-1}$ corresponding to the symmetric stretching vibrations of carboxylate group. As expected, a sharp peak at $1399 \mathrm{~cm}^{-1}$ was

John Wiley \& Sons, Inc.

This article is protected by copyright. All rights reserved. 
found in the FT-IR spectrum of semi-IPN PAAc/PASP hydrogel (Figure 3c). The peaks at $1520 \mathrm{~cm}^{-1}$ and $1582 \mathrm{~cm}^{-1}$ in the FTIR spectrum of PASP (Figure $3 \mathrm{~b}$ ) indicated the amide group in PASP. A strong peak associated with the amide group was also found at $1568 \mathrm{~cm}^{-1}$ in the FT-IR spectrum of the semi-IPN PAAc/PASP hydrogel (Figure 3c). These results confirmed the presence of PASP in the semi-IPN PAAc/PASP hydrogel. On the other hand, the broadband at $\sim 3270 \mathrm{~cm}^{-1}$ in the FT-IR spectra of PASP (Figure 3b) and semi-IPN PAAc/PASP hydrogel (Figure 3c) represent the stretching bands

of the $-\mathrm{NH}_{2}$ group, while the peak at $3387 \mathrm{~cm}^{-1}$ was attributed to the $-\mathrm{NH}-$ stretching vibration of PASP in the semi-IPN PAAc/PASP hydrogel. None of these bands were noted in the FT-IR spectrum of PAA (Figure 3a), thereby verifying the incorporation of PASP in semi-IPN PAAc/PASP hydrogel structure.

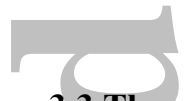

\subsection{Thermal analysis}

TGA tracings of PAAc and semi-IPN PAAc/PASP hydrogels are depicted in Figure 4. The weight (1)

loss in the hydrogel was mainly caused by the thermal decomposition of polymer and the splitting of polymer chain. The hydrogels underwent three stages of thermal decomposition. At the first stage of decomposition, the weight losses in semi-IPN PAAc/PASP hydrogels (IPN 37-25 and IPN 37-F20) and PAAc hydrogels (SC, PAA 37-25 and PAA 37-F20) were $17 \%$ and $13 \%$, respectively. The weight losses in the hydrogels at this stage were mainly associated to the loss of moisture content from the hydrogels. Beyond this stage, the splitting and breaking of main polymer chains in hydrogels occurred and the most intensive decomposition rate began at $340^{\circ} \mathrm{C}$. The major decomposition of the hydrogel took place in the second stage of thermal decomposition $\left(220-340^{\circ} \mathrm{C}\right)$, whereas the maximum decomposition occurred in the third stage of thermal decomposition $\left(340-440^{\circ} \mathrm{C}\right)$. The residual mass percentages of the PAAc and semi-IPN PAAc/PASP hydrogels were $\sim 10 \%$ and $\sim 30 \%$, respectively. The $t_{1 / 2}$ of semi-IPN PAAc/PASP hydrogel $\left(381^{\circ} \mathrm{C}\right)$ was higher than that of PAAc hydrogel $\left(355^{\circ} \mathrm{C}\right)$. These results demonstrated that the thermal stability of semi-IPN PAAc/PASP

John Wiley \& Sons, Inc. 
hydrogel were greatly enhanced by the incorporation of PASP into PAAc hydrogels. This might be attributed to the good thermal stability and the high thermal resistance of PASP.

\subsection{Swelling kinetics of hydrogel}

Figure 5 depicted the swelling kinetics of the hydrogels. All the hydrogels exhibited the swelling tendency shortly after they were immersed in $0.05 \mathrm{M}$ PBS solution. The hydrogel swelling was reliant on the solvent diffusion and polymer network relaxation ${ }^{36}$. Upon transfer of hydrogel from $0.15 \mathrm{M}$ PBS solution to $0.05 \mathrm{M}$ PBS solution, the difference of mobile ion concentration between the interior of the hydrogel and the environmental solution increased. Water molecules migrated into the dynamically formed spaces between polymer chains. This phenomenon was ascribed by an increase in

the osmotic pressure of hydrogels. The imbalance in osmotic pressure led to the flush-in of water molecules. Consequently, the ion gradient was compensated by the swelling of hydrogel.

The second-order swelling kinetics $\operatorname{model}^{26}$ was used to analyze the swelling kinetics of hydrogels. Empirically, the swelling kinetics were perfectly fitted with a second-order rate equation as given in equation (3). The swelling kinetic at any pre-determined time $t$ can be expressed by the $\mathrm{S}_{\mathrm{t}}$ of the hydrogel, which is the water uptake of hydrogel from its surrounding. A linear correlation between $t / s$ and $t$ was obtained upon the integration of equation (3). The Figure 6 was plotted based on equation (4), where $\mathrm{S}_{\mathrm{eq}(\mathrm{calc})}$ and $\mathrm{k}_{\mathrm{s}}$ were obtained from the slope and intercept of the linear regression, respectively.

The calculated swelling kinetics parameters and the statistical parameters of these fittings are depicted in Table 2. A good fitting of the experimental swelling data to Schott's swelling kinetics expression ${ }^{26}$, ${ }^{37}$ was indicated by a high regression coefficient, $R^{2}$, (i.e., 0.9994 to 1 ), a low chi-square value, $\chi^{2}$, (i.e., 0.002625 to 0.01403 ), and a high regression $F$ value (i.e., 18875 to 251983 ) of the fittings. Furthermore, the $\mathrm{S}_{\text {eq(alc) }}$ of the hydrogels was found to be very close to its $\mathrm{S}_{\text {eq(exp). }}$ These results 
confirmed that the ionic-strength responsiveness of hydrogel perfectly obeys the second-order rate expression by $\mathrm{Schott}^{26}$.

Relaxation rate of the polymer network was highly dependent on the properties of hydrogel, such as rigidity, hydrophilicity, cross-linking density, dimension and proportion of amorphous region of hydrogel ${ }^{27}$. The presence of PASP in semi-IPN hydrogel increased the overall number of ionized hydrophilic $-\mathrm{COOH}$ groups in the hydrogel. As shown in Figure 5 and Table 2, the incorporation of PASP into the PAAc hydrogel structure could significantly improve the swelling and deswelling rates of the hydrogels. The IPN 37-25 has at least a two-fold increase in both $\mathrm{k}_{\mathrm{s}}$ and $\mathrm{r}_{0}$ in comparison to that of PAA $37-25$.

The electrostatic repulsion force was strongly associated to the proportion of attached ionizable groups in the hydrogel ${ }^{16}$. The synthesized semi-IPN PAAc/PASP hydrogels were responsive to $\mathrm{pH}$ change. At $\mathrm{pH} 7.4$, the pendant carboxylic acid $(-\mathrm{COOH})$ and ammonium ions $\left(-\mathrm{NH}^{3+}\right)$ in the hydrogel can be deprotonated into carboxylic ions $\left(-\mathrm{COO}^{-}\right)$and amine groups $\left(-\mathrm{NH}_{2}\right)$, respectively. The electrostatic repulsion force occurred within hydrogel were mainly attributed to the anionic carboxylic ions, which were the dominant repulsion force that induces the swelling of hydrogel. The enhanced electrostatic repulsion led to a higher porosity of hydrogel, which were reaffirmed by the FE-SEM results (Figures $2 \mathrm{c}$ and d). The porous microstructure in semi-IPN PAAc/PASP hydrogel acted as the hydrophilic micro-channels that accelerated the diffusion of water molecules from the PBS solution into the hydrogel, thus enhancing the responsiveness of hydrogel. Hence, it can be concluded that the number of charged groups within the hydrogel and the hydrophilicity of the hydrogel played an important role in its swelling kinetics (Table 2). Overall, the ionic-strength sensitivity of semi-IPN PAAc/PASP hydrogel was improved with the presence of PASP.

As shown in Figure 5, the freeze-polymerized hydrogels (i.e., PAA 37-F20 and IPN 37-F20, respectively) exhibited a faster swelling rate in response to the external ionic strength changes than 
those prepared at room temperature (i.e., PAA 37-25 and IPN 37-25, respectively). Based on the results shown in Table 2 , the freezing polymerization greatly improved the $r_{0}$ of hydrogel but exerted a minimal influence on the $\mathrm{k}_{\mathrm{s}}$. After the first-step polymerization, mobile water molecules diffused into the partially-formed hydrogel prior to freezing at $-20^{\circ} \mathrm{C}$. Prior to the freezing step (at $-20^{\circ} \mathrm{C}$ ), the free water molecules diffused into the partially-formed hydrogel during the first-step polymerization ${ }^{38}$. The water molecules started to crystallize at the freezing temperature. The gel-forming solution containing the reactive monomers, cross-linker, initiator and accelerator, was polymerized to form the hydrogel, while the void space filled with ice crystals formed the pores after thawing, thereby synthesizing a polymer network with a more open channel structure ${ }^{38}$. Since the volume requirement of the crystallized water molecules was larger than its liquid state ${ }^{38}$, the mean pore size of hydrogels prepared by freezing polymerization was increased. This result was reaffirmed by the FE-SEM images (Figure 2). The surface-to-volume ratio of the hydrogel was increased due to its large and interconnected porous structure ${ }^{38}$. The crystallized water molecules present in the hydrogel during the polymerization rendered a highly porous structure of the hydrogel, enhancing the hydrogel's water absorbency and swelling capability. On the contrary, the dense and less porous structures found in PAA $37-25$ and SC highly resisted the diffusion of water molecules into the hydrogels, thus explaining their low response rates towards the ionic strength of solution. One could envisage that a higher porosity will result in a rapid response rate because of a larger mesh size between the polymer chains in the hydrogel network. The larger mesh size enables the diffusions of solute and solvent more rapidly through the hydrogel.

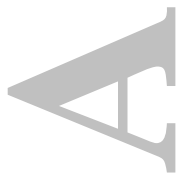

\subsection{Deswelling kinetics of hydrogel}

The deswelling kinetics of the PAAc and semi-IPN PAAc/PASP hydrogels were investigated by allowing the hydrogel to deswell in a buffer having a higher ionic strength. Overall, as observed in Figure 7, the water content of the hydrogels decreased with an increase in ionic strength of PBS

John Wiley \& Sons, Inc. 
solution at $\mathrm{pH}$ 7.4. The diffusion of water molecules into the hydrogels was kinetically limited by the ion gradient. This was ascribed to a decrease in the osmotic pressure of the hydrogels, which was caused by the increase in ionic strength. Consequently, the difference in mobile ion concentrations between the interior of hydrogel and the environmental bath would be compensated by a decrease in swelling of hydrogel.

Similar to the swelling behavior, the ability of the hydrogel to retain water was significantly dependent on the chemical composition of the hydrogels. The ability of hydrogels to retain water was found to be in the decreasing order of: IPN 37-F20> IPN 37-25> PAA 37-F20> PAA 37-25. This trend is in agreement with the overall number of anionic hydrophilic $\mathrm{COOH}$ groups present in the hydrogel. As mentioned earlier, the porous structure of the hydrogel and the hydrophilicity of incorporated PASP were responsible for the formation of water liberating micro-channels in the semiIPN PAAc/PASP hydrogel network ${ }^{39}$.

The results shown in Figure 7 demonstrate that the freeze-polymerized hydrogel (i.e., PAA 37-F20 and IPN 37-F20, respectively) possessed a faster deswelling than those conventionally polymerized hydrogel (i.e., PAA 37-25 and IPN 37-25, respectively). The higher surface-to-volume ratio of freezepolymerized hydrogels accelerated the water diffusion ${ }^{38}$. Furthermore, the larger pore size in freezepolymerized hydrogels (i.e., PAA 37-F20 and IPN 37-F20) allowed the freed water to diffuse out quickly, resulting in the faster deswelling of the hydrogels.

The PAA 37-25 and SC hydrogels exhibited the slowest rate of deswelling. The glassy and rigid layers found in them (Figures 2a and e) were responsible to their high resistances for water diffusion. On the contrary, IPN 37-F20 had the fastest rate of deswelling and a high rate of water diffusion. Due to its large mean pore size and high porosity.

Overall, SC and PAA 37-25 exhibited the similar patterns of swelling (Figure 5) and deswelling (Figure 7), indicating that the high temperature $\left(37^{\circ} \mathrm{C}\right)$ used in the first-step polymerization solely 
accelerated the polymerization process, as reaffirmed by their similar non-porous microstructures (Figure 2).

\subsection{Ionic-strength dependence of the $S_{\mathrm{eq}}$ of hydrogel}

The $\mathrm{S}_{\text {eq }}$ of PAAc and semi-IPN PAAc/PASP hydrogels was investigated using $0.05 \mathrm{M}$ and $0.15 \mathrm{M}$ PBS solutions at $\mathrm{pH}$ 7.4. From Figure 8, it can be seen that the semi-IPN PAAc/PASP hydrogels have at least 1.13 -fold increase in $\mathrm{S}_{\mathrm{eq}}$ as compared to their respective PAAc hydrogels. This may be ascribed to the increased number of hydrophilic anionic carboxylate functional groups $\left(\mathrm{COO}^{-}\right)$in semi-IPN PAAc/PASP hydrogel. The increase in electrostatic repulsion force was believed to contribute the highly expanded structure in hydrogel, leading to a higher $\mathrm{S}_{\mathrm{eq}}$ value as shown in Table 2 .

\section{The $S$}

The $\mathrm{S}_{\text {eq }}$ of the freeze-polymerized PAAc hydrogel (PAA 37-F20) was at least 1.28 times higher than that of the conventionally polymerized PAAc hydrogel (i.e., SC). This was mainly attributed to the pore formation during freezing polymerization. The pore size and porosity of the hydrogel played an important role in the $\mathrm{S}_{\mathrm{eq}}$ of hydrogels. During the swelling process, the pre-formed pores inside the polymer network were rapidly filled with the water molecules. Meanwhile, the ability of polymer chains to attract water molecules from the surrounding depends on the attractive force between the water molecules and polymer's functional groups, particularly carboxylate. In a nut shell, the $\mathrm{S}_{\mathrm{eq}}$ of hydrogel was mainly governed by the solvation of polymer chain and the filling of the pores by the solvent. One could envisage that a higher porosity will result in a high swelling ratio because of a larger size of pore formed by the polymer chains in the hydrogel network. The larger pore size caused a loose structure, which greatly improved the water absorbent capacity of the hydrogel because the large pores allowed a greater volume of void space to be filled by the solvent. The increasing pore size and porosity of the hydrogel permitted a greater access of water molecules to the hydrogel, thus further expanding the network of hydrogels. Hence, SC hydrogel has the lowest $S_{\text {eq }}$ value because of 
its dense and less porous structure (Figure 2a). Furthermore, all the $S_{\text {eq(exp) }}$ values were in good agreement with the respective $S_{\text {eq(calc) }}$ values as shown in Table 2 .

\subsection{Oscillatory swelling/deswelling of hydrogel}

The oscillatory swelling-deswelling of hydrogels was investigated by alternating the ionic strength of PBS solutions ( $\mathrm{pH} 7.4$ ) between $0.15 \mathrm{M}$ and $0.05 \mathrm{M}$. As seen from Figure 9, the semi-IPN PAAc/PASP hydrogels (IPN 37-25 \& IPN 37-F20) demonstrated the best swelling-deswelling reversibility in response to the change in ionic strength of PBS solution. The excellent swelling-deswelling reversibility of semi-IPN PAAc/PASP hydrogel was due to the incorporation of PASP in PAAc hydrogel structure.

The durations required by IPN 37-F20 to swell and deswell to its equilibrium state were 12 min and $21 \mathrm{~min}$, respectively. On the contrary, the durations of equilibrium swelling and deswelling for IPN 37-F20 were $15 \mathrm{~min}$ and $24 \mathrm{~min}$, respectively. Hence, we can conclude that the swelling-deswelling processes for IPN 37-F20 was relatively faster than IPN 37-25 in a stimulated physiological fluid. The porous structure of semi-IPN PAAc/PASP hydrogels was believed to be the reason behind the relatively fast expansion-shrinking of freeze-polymerized hydrogels in the physiological fluid.

Among the five types of hydrogels, IPN 37-F20 demonstrated the best ionic-strength sensitivity due to its largest difference in equilibrium swelling and deswelling states. PAAc hydrogels (i.e., SC, PAA 37-25 and PAA 37-F20) exhibited poor ionic-strength reversibility. Moreover, the swelling ratio of PAAc hydrogel increased gradually with the increasing number of oscillatory cycles. This trend could be due to the relatively slow deswelling rate of the PAAc hydrogel as compared to its swelling rate.

John Wiley \& Sons, Inc. 
Overall, the excellent response of IPN 37-F20 hydrogels towards the change in ionic strength makes them suitable to be used in applications demanding the rapid swelling-deswelling of hydrogels, for example: in controlled release of drug from the matrix, or as a component in biosensor ${ }^{12-14}$.

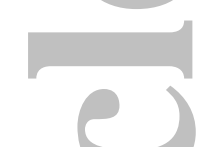

\section{CONCLUSIONS}

In this study, a two-step free-radical polymerization was applied to the synthesis of semi-IPN PAAc/PASP hydrogel for the aim of improving its ionic-strength responsivity. The swelling behavior of the hydrogel was perfectly fitted to Schott's second-order swelling kinetics model. Overall, the swelling and deswelling rates of PAAc hydrogel have been improved by the freezing polymerization step as well as the incorporation of PASP into the hydrogel's structure. IPN 37-F20 is a good candidate of hydrogel for use in practical applications, owing to its excellent sensitivity and reversibility toward ionic strength. The semi-IPN PAAc/PASP hydrogel can be anticipated as a (4) promising material used in biosensor, biomedical, and pharmaceutical fields.

$$
\text { (1) }
$$

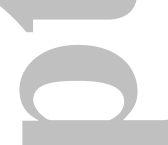

\section{ACKNOWLEDGEMENTS}

Swee Lu Lim was supported by the School of Engineering and Advanced Engineering Platform (AEP), Monash University Malaysia under the Higher Degree Research (HDR) Scholarship.

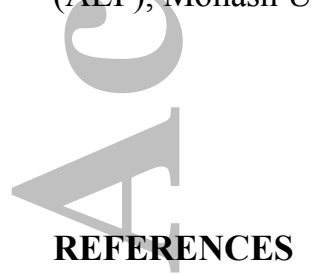

1 Y. Zhao, T. Tan, T. Kinoshita, Journal of Polymer Science Part B: Polymer Physics 2010, 48, 666-671.

2 D. Schmaljohann, Drug Delivery Reviews 2006, 58, 1655-1670.

3 A. S. Hoffman, P. S. Stayton, V. Bulmus, G. Chen, J. Chen, C. Cheung, A. Chilkoti, Journal of

Biomedical Materials Research 2000, 52, 577-586.

John Wiley \& Sons, Inc.

This article is protected by copyright. All rights reserved. 
4 A. S. Hoffman, Advanced Drug Delivery Reviews 2013, 65, 10-16.

5 S. Jin, M. Liu, F. Zhang, S. Chen, A. Niu, Polymer 2006, 47, 1526-1532.

6 T. Tanaka, I. Nishio, S.-T. Sun, S. Ueno-Nishio, Science 1982, 218, 467-469.

7 Y. H. Bae, T. Okano, R. Hsu, S. W. Kim, Die Makromolekulare Chemie, Rapid Communications $1987,8,481-485$.

8 G. Lin, S. Chang, C.-H. Kuo, J. Magda, F. Solzbacher, Sensors and Actuators B: Chemical 2009, 136, 186-195.

9 A. Agarwal, R. C. Unfer, S. K. Mallapragada, Biomaterials 2008, 29, 607-617.

10 M. Dadsetan, Z. Liu, M. Pumberger, C. V. Giraldo, T. Ruesink, L. Lu, M. J. Yaszemski, Biomaterials 2010, 31, 8051-8062.

11 Y.-C. Qian, P.-C. Chen, X.-Y. Zhu, X.-J. Huang, RSC Advances 2015, 5, 44031-44040.

12 J. H. Holtz, S. A. Asher, Nature 1997, 389, 829-832.

13 S. A. Asher, V. L. Alexeev, A. V. Goponenko, A. C. Sharma, I. K. Lednev, C. S. Wilcox, D. N. Finegold, Journal of the American Chemical Society 2003, 125, 3322-3329.

14 V. L. Alexeev, A. C. Sharma, A. V. Goponenko, S. Das, I. K. Lednev, C. S. Wilcox, D. N. Finegold, S. A. Asher, Analytical Chemistry 2003, 75, 2316-2323.

15 S. J. Kim, K. J. Lee, I. Y. Kim, Y. M. Lee, S. I. Kim, Journal of Applied Polymer Science 2003, 90, 3310-3313.

16 Y. Zhao, J. Kang, T. Tan, Polymer 2006, 47, 7702-7710.

17 O. E. Philippova, D. Hourdet, R. Audebert, A. R. Khokhlov, Macromolecules 1997, 30, 82788285.

18 J. F. Yaung, T. Kwei, Journal of Applied Polymer Science 1998, 69, 921-930.

19 M. Karbarz, W. Hyk, Z. Stojek, Electrochemistry Communications 2009, 11, 1217-1220.

20 S. H. Gehrke, Advanced Polymer Science 1993, 110, 81-144.

21 C. Liu, X. Gan, Y. Chen, Starch - Stärke 2011, 63, 503-511.

22 W. Xue, S. Champ, M. B. Huglin, T. G. Jones, European Polymer Journal 2004, 40, 467-476.

23 H. Liu, M. Liu, J. Huang, L. Ma, J. Chen, Polymer Advanced Technology 2009, 20, 1152-1156.

24 A. Pourjavadi, A. M. Harzandi, H. Hosseinzadeh, European Polymer Journal 2004, 40, 1363-

1370.

25 J. Foreman, C. Lundgren, P. Gill, In Technical Papers of the Annual Technical Conferencesociety of Plastics Engineers Incorporated 1993, 3025.

26 H. Schott, Journal of Macromolecular Science, Part B: Physics 1992, 31, 1-9.

27 Y. Yin, Y. Yang, H. Xu, Journal of Polymer Science Part B: Polymer Physics 2001, 39, 3128-3137.

28 D. Saraydın, Y. Işıkver, E. Karadağ, N. Sahiner, O. Güven, Nuclear Instruments and Methods in Physics Research Section B: Beam Interactions with Materials and Atoms 2002, 187, 340-344.

29 E. Karadağ, Ö. B. Üzüm, D. Saraydin, O. Güven, International Journal of Pharmaceutics 2005, $301,102-111$.

30 M. Tomida, M. Yabe, Y. Arakawa, Polymer 1997, 38, 2791-2794.

John Wiley \& Sons, Inc.

This article is protected by copyright. All rights reserved. 
31 L. Leibler, Macromolecules 1980, 13, 1602-1617.

32 X.-Z. Zhang, Y.-Y. Yang, F.-J. Wang, T.-S. Chung, Langmuir 2002, 18, 2013-2018.

33 C. Nakamoto, T. Motonaga, M. Shibayama, Macromolecules 2001, 34, 911-917.

34 C. Alvarez-Lorenzo, O. Guney, T. Oya, Y. Sakai, M. Kobayashi, T. Enoki, Y. Takeoka, T.

Ishibashi, K. Kuroda, K. Tanaka, Macromolecules 2000, 33, 8693-8697.

35 W. Xue, I. W. Hamley, M. B. Huglin, Polymer 2002, 43, 5181-5186.

36 X. Qu, A. Wirsén, A. C. Albertsson, Journal of Applied Polymer Science 1999, 74, 3186-3192.

37 B. Mandal, S. K. Ray, Carbohydrate Polymers 2013, 98, 257-269.

38 X.-Z. Zhang, R.-X. Zhuo, Macromolecules Chemistry and Physics 1999, 200, 2602-2605.

39 M. Liu, H. Su, T. Tan, Carbohydrate Polymers 2012, 87, 2425-2431.
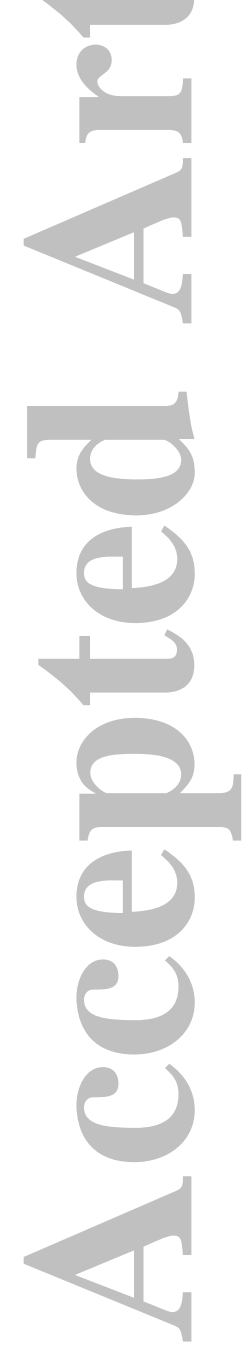

John Wiley \& Sons, Inc.

This article is protected by copyright. All rights reserved. 


\section{FIGURES}

Figure 1. Synthesis steps of (a) PAAc hydrogel and (b) semi-IPN PAAc/PASP hydrogel.

Figure 2. Cross-sectional FE-SEM images of the hydrogels.

Figure 3. FT-IR spectra of (a) PAAc, (b) PASP and (c) semi-IPN PAAc/PASP hydrogels.

Figure 4. TGA analyses of SC, PAAc and semi-IPN PAAc/PASP hydrogels.

(1)

Figure 5. Swelling kinetics of the hydrogels incubated in 0.05M PBS solution (pH 7.4). The hydrogels were first equilibrated in $0.15 \mathrm{M}$ PBS solution ( $\mathrm{pH} 7.4$ ) for 24 hours.

Figure 6. Linear regression of swelling isotherms for the hydrogels in response to the changes in ionic strength of PBS solution. The swelling data were fitted using equation (4).

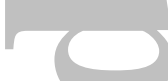

Figure 7. Deswelling kinetics of the hydrogels incubated in $0.15 \mathrm{M}$ PBS solution (pH 7.4). The hydrogels were pre-equilibrated in 0.05M PBS solution ( $\mathrm{pH} 7.4$ ) for 24 hours.

Figure 8. $\mathrm{S}_{\mathrm{eq}}$ of the hydrogels in PBS solution (pH 7.4) prepared at different ionic strength.

Figure 9. Time-dependent ionic-strength response of PAAc and semi-IPN PAAc/PASP hydrogels incubated in PBS solution at $\mathrm{pH}$ 7.4. The ionic strength of PBS solution was cycled between $0.05 \mathrm{M}$ and $0.15 \mathrm{M}$ every $40 \mathrm{~min}$ for a total of $160 \mathrm{~min}$.

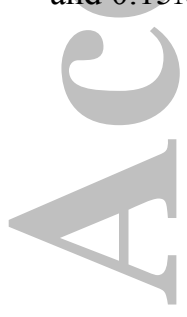

John Wiley \& Sons, Inc. 


\section{TABLES}

Table 1. Feed composition and polymerization conditions for the preparation of PAAc and semi-IPN
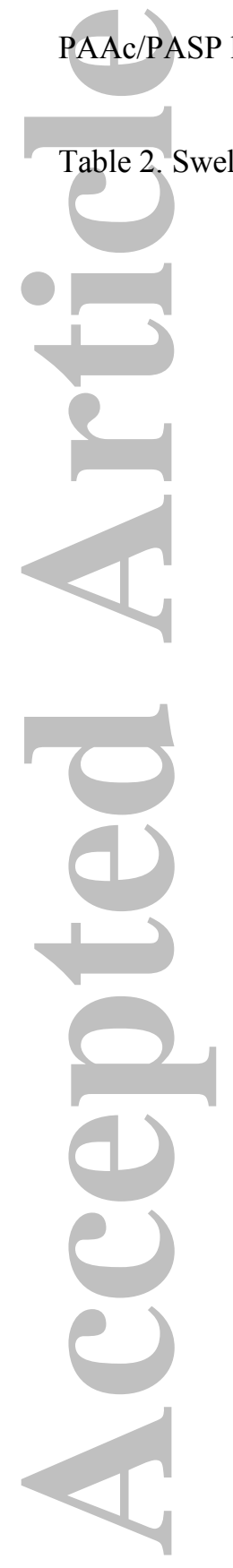

John Wiley \& Sons, Inc.

This article is protected by copyright. All rights reserved. 


\section{FIGURES}

(a)

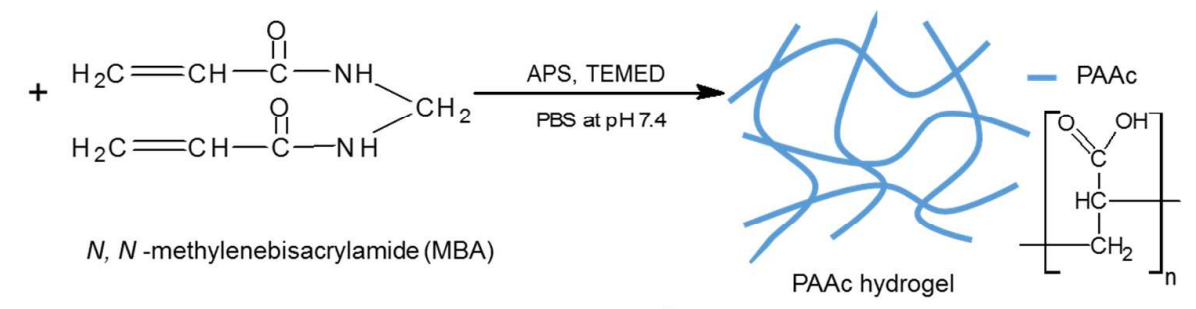

(b)

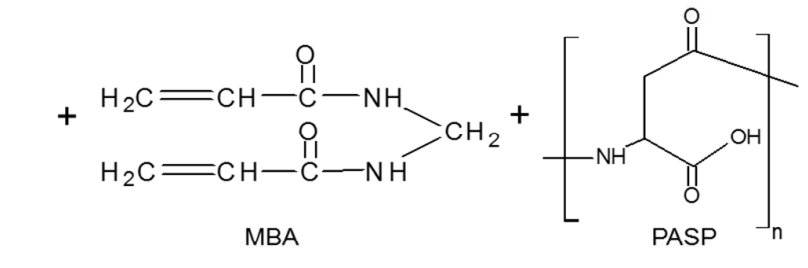

Acrylic acid

MBA

PAAc hydroge

Acrylic acid

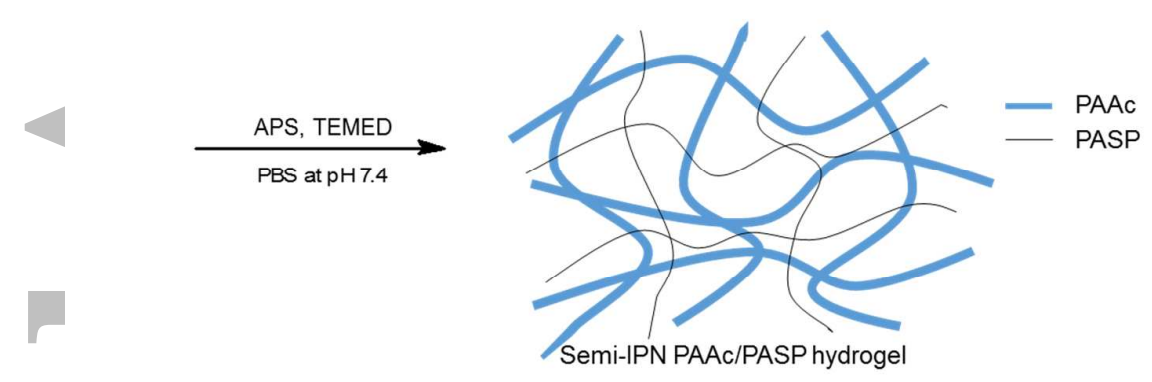

Figure 1. Synthesis steps of (a) PAAc hydrogel and (b) semi-IPN PAAc/PASP hydrogel.

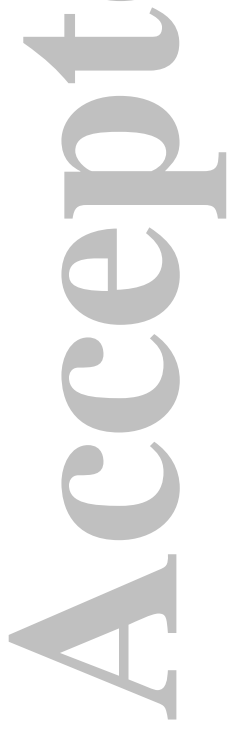

John Wiley \& Sons, Inc.

This article is protected by copyright. All rights reserved. 


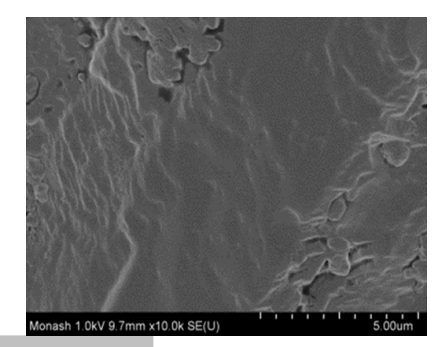

(a) PAA $37-25$

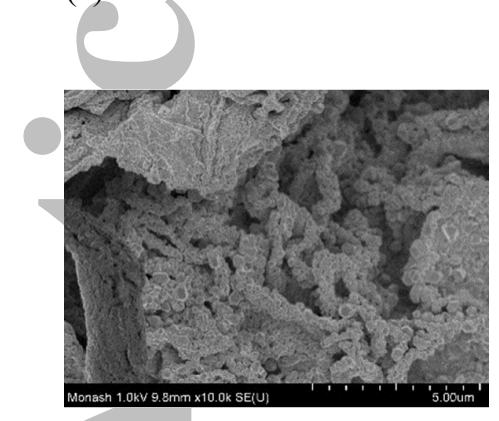

(d) IPN 37-F20

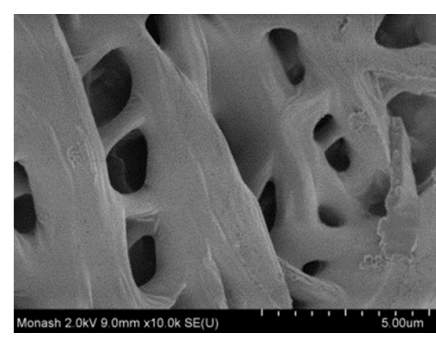

(b) PAA 37-F20

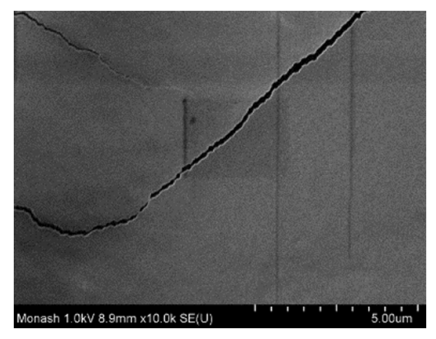

(e) $\mathrm{SC}$

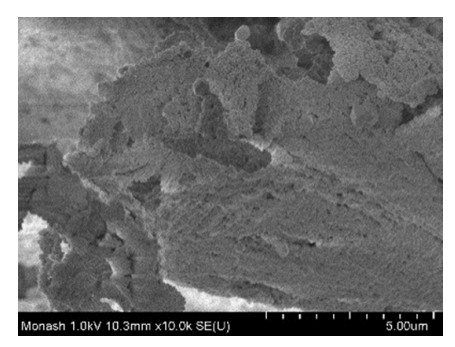

(c) IPN 37-25

Figure 2. Cross-sectional FE-SEM images of the hydrogels.

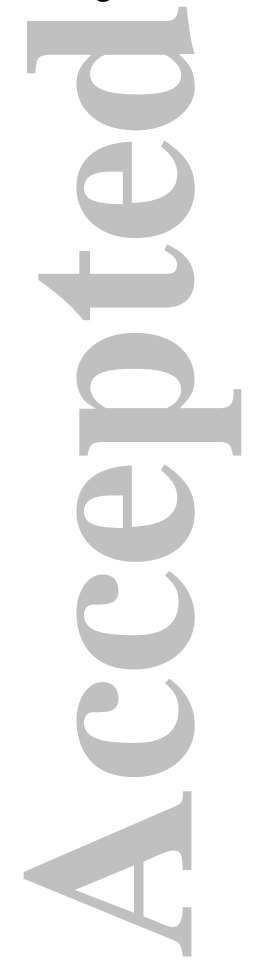

John Wiley \& Sons, Inc.

This article is protected by copyright. All rights reserved. 


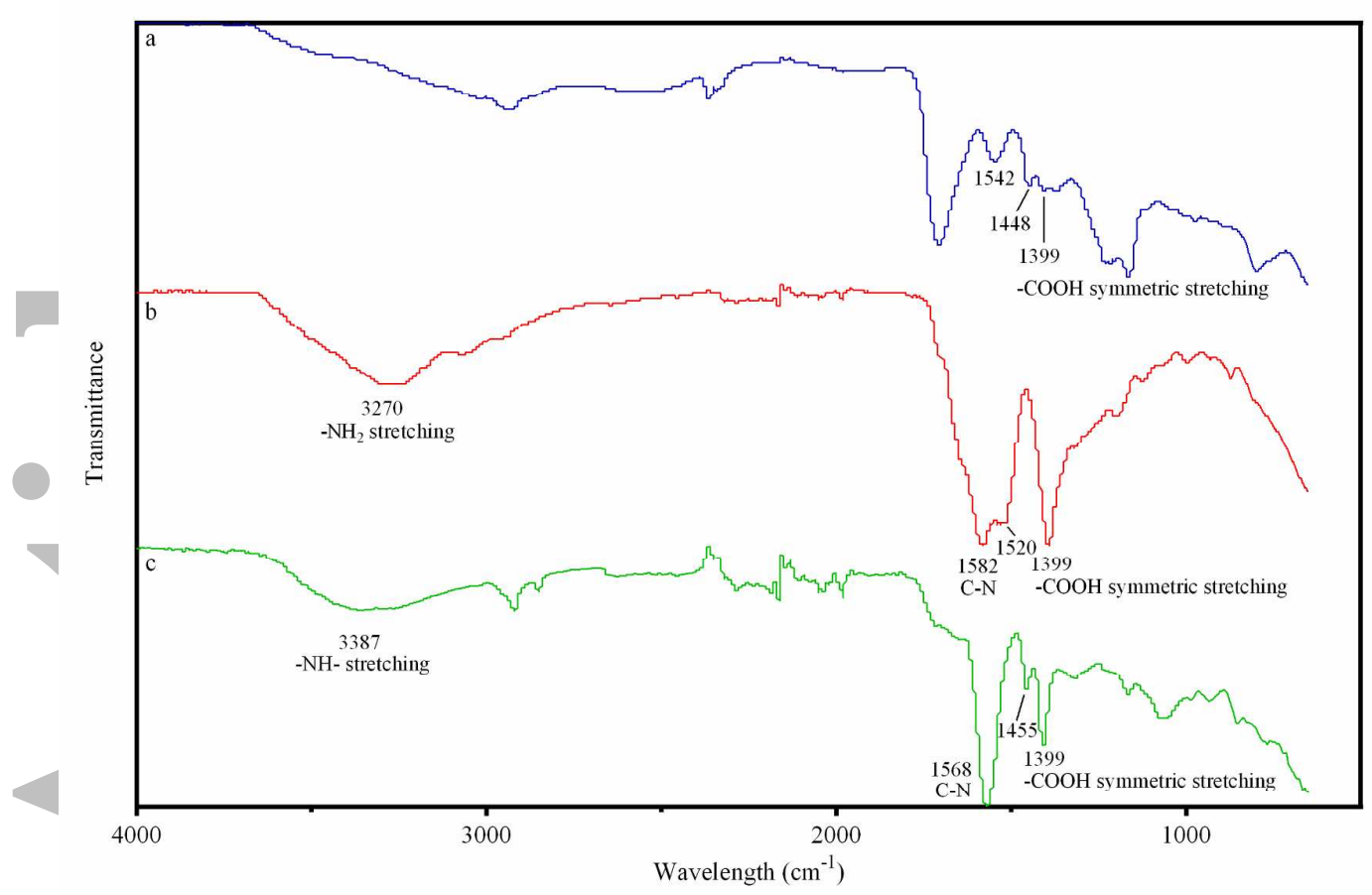

Figure 3. FT-IR spectra of (a) PAAc, (b) PASP and (c) semi-IPN PAAc/PASP hydrogels.

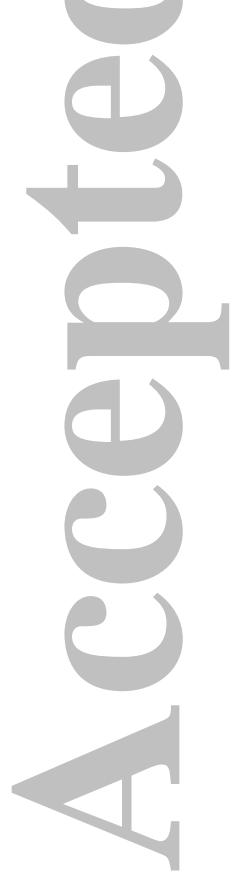

John Wiley \& Sons, Inc.

This article is protected by copyright. All rights reserved. 


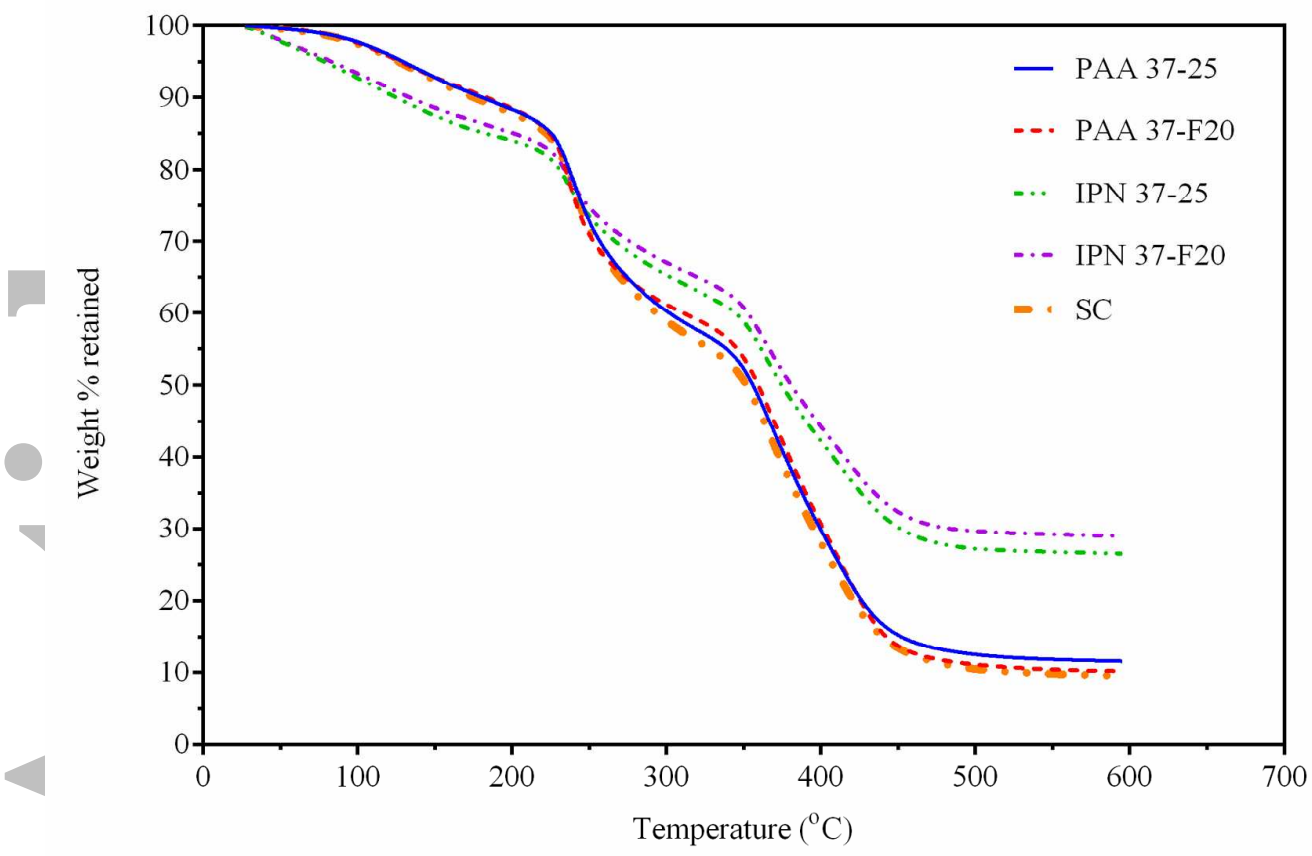

Figure 4. TGA analyses of SC, PAAc and semi-IPN PAAc/PASP hydrogels.

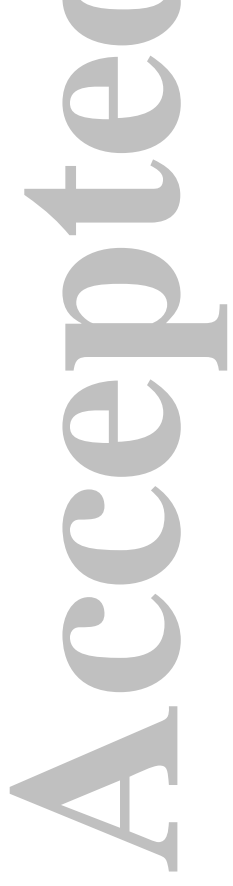

John Wiley \& Sons, Inc.

This article is protected by copyright. All rights reserved. 


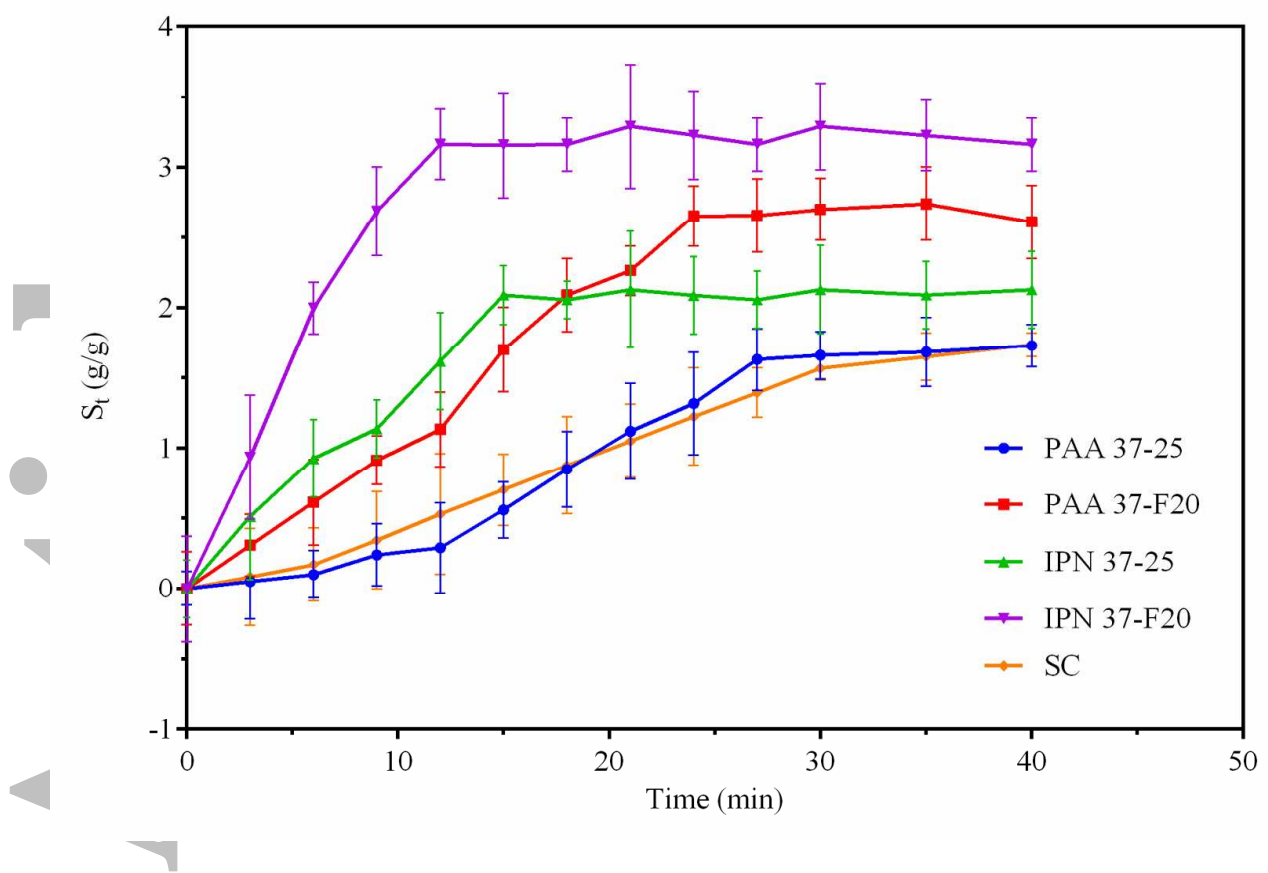

Figure 5. Swelling kinetics of the hydrogels incubated in 0.05M PBS solution (pH 7.4). The hydrogels were first equilibrated in $0.15 \mathrm{M}$ PBS solution ( $\mathrm{pH} 7.4$ ) for 24 hours.

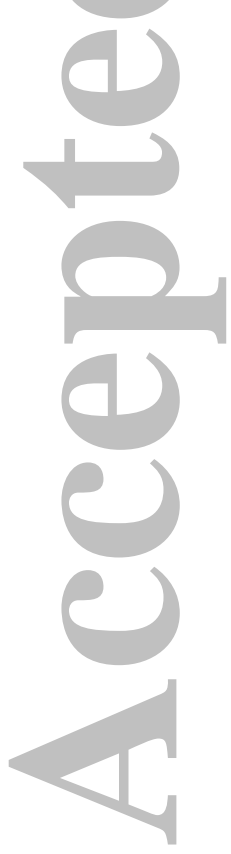

John Wiley \& Sons, Inc.

This article is protected by copyright. All rights reserved. 


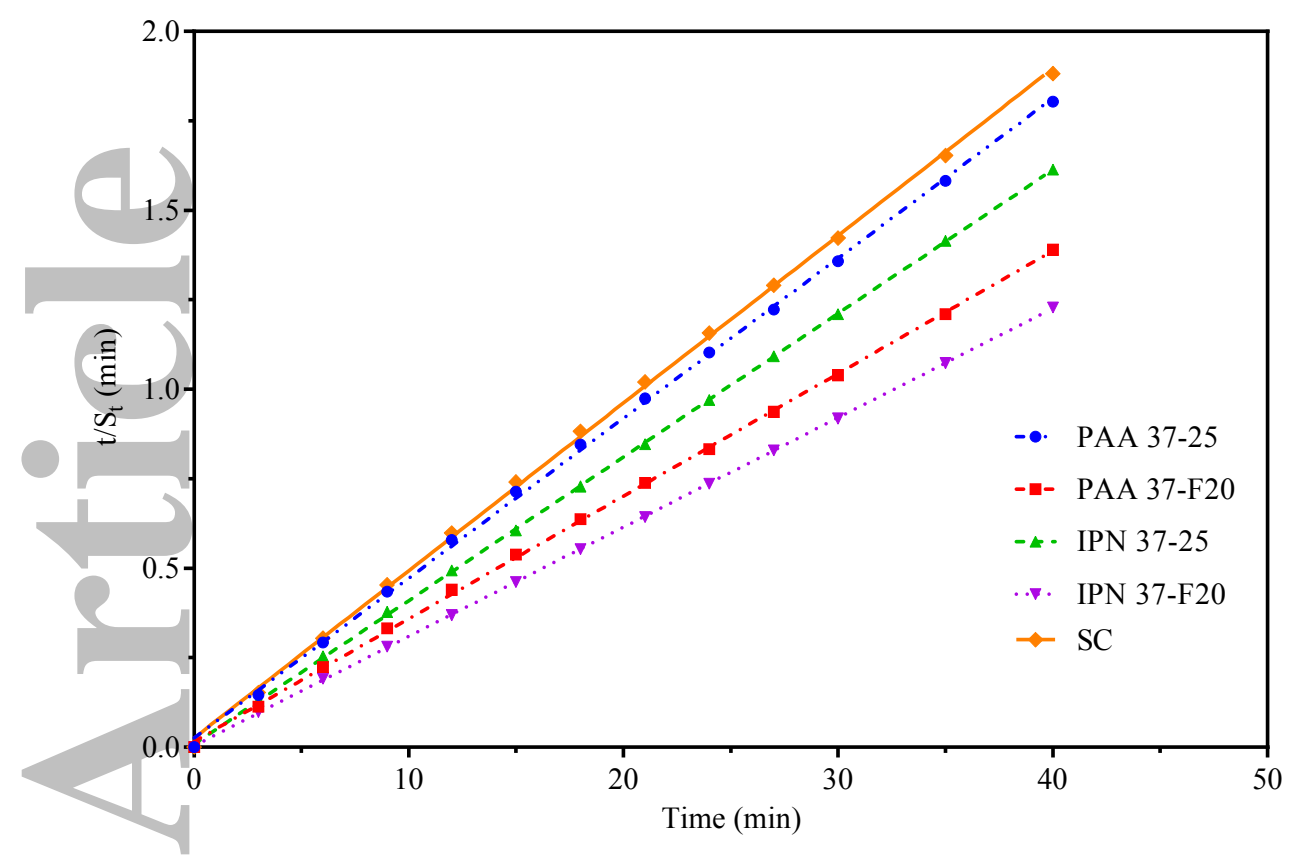

Figure 6. Linear regression of swelling isotherms for the hydrogels in response to the changes in ionic strength of PBS solution. The swelling data were fitted using equation (4).

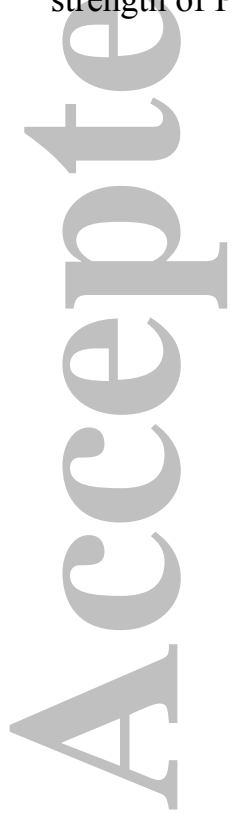

John Wiley \& Sons, Inc.

This article is protected by copyright. All rights reserved. 


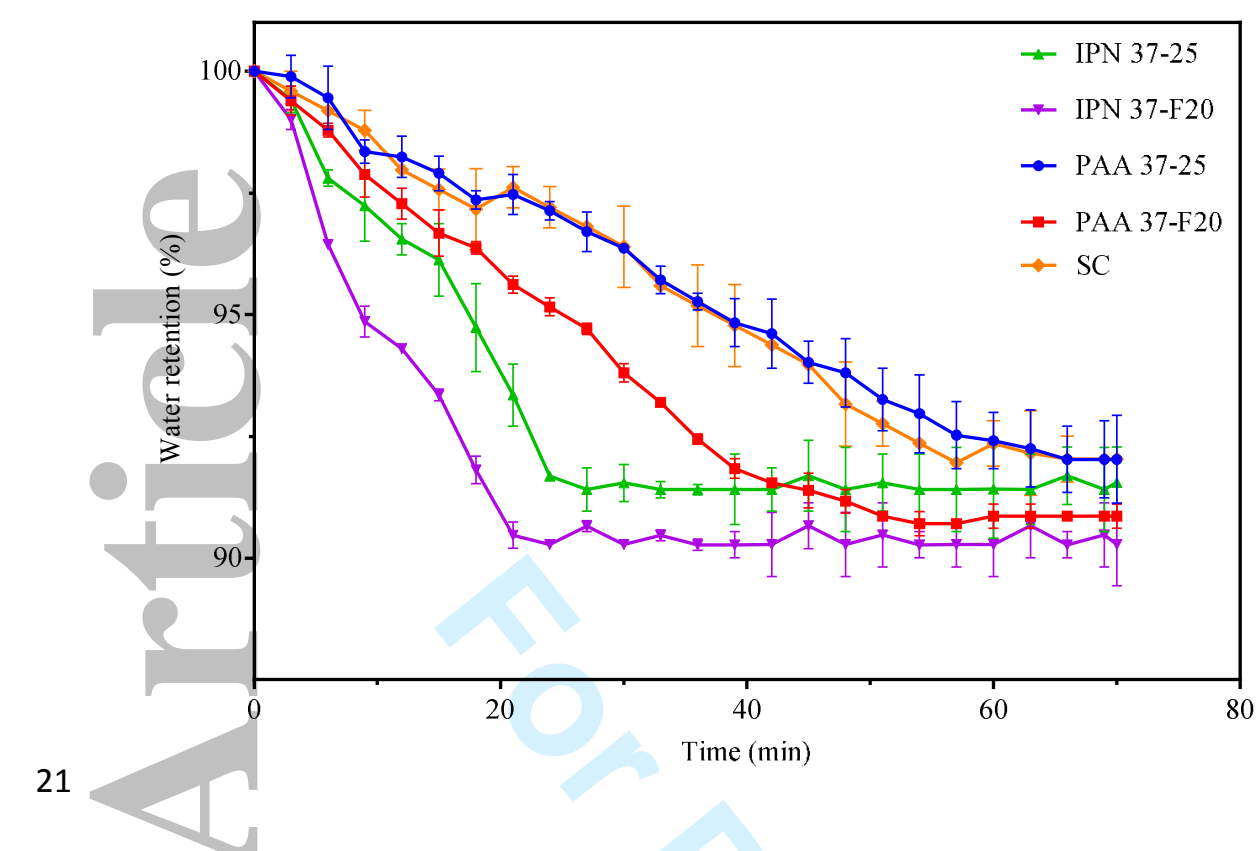

22 Figure 7. Deswelling kinetics of the hydrogels incubated in $0.15 \mathrm{M}$ PBS solution (pH 7.4). The 23 hydrogels were pre-equilibrated in 0.05M PBS solution ( $\mathrm{pH} 7.4$ ) for 24 hours.

24

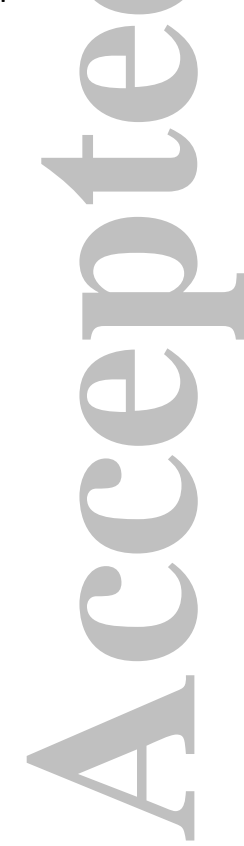

John Wiley \& Sons, Inc. 


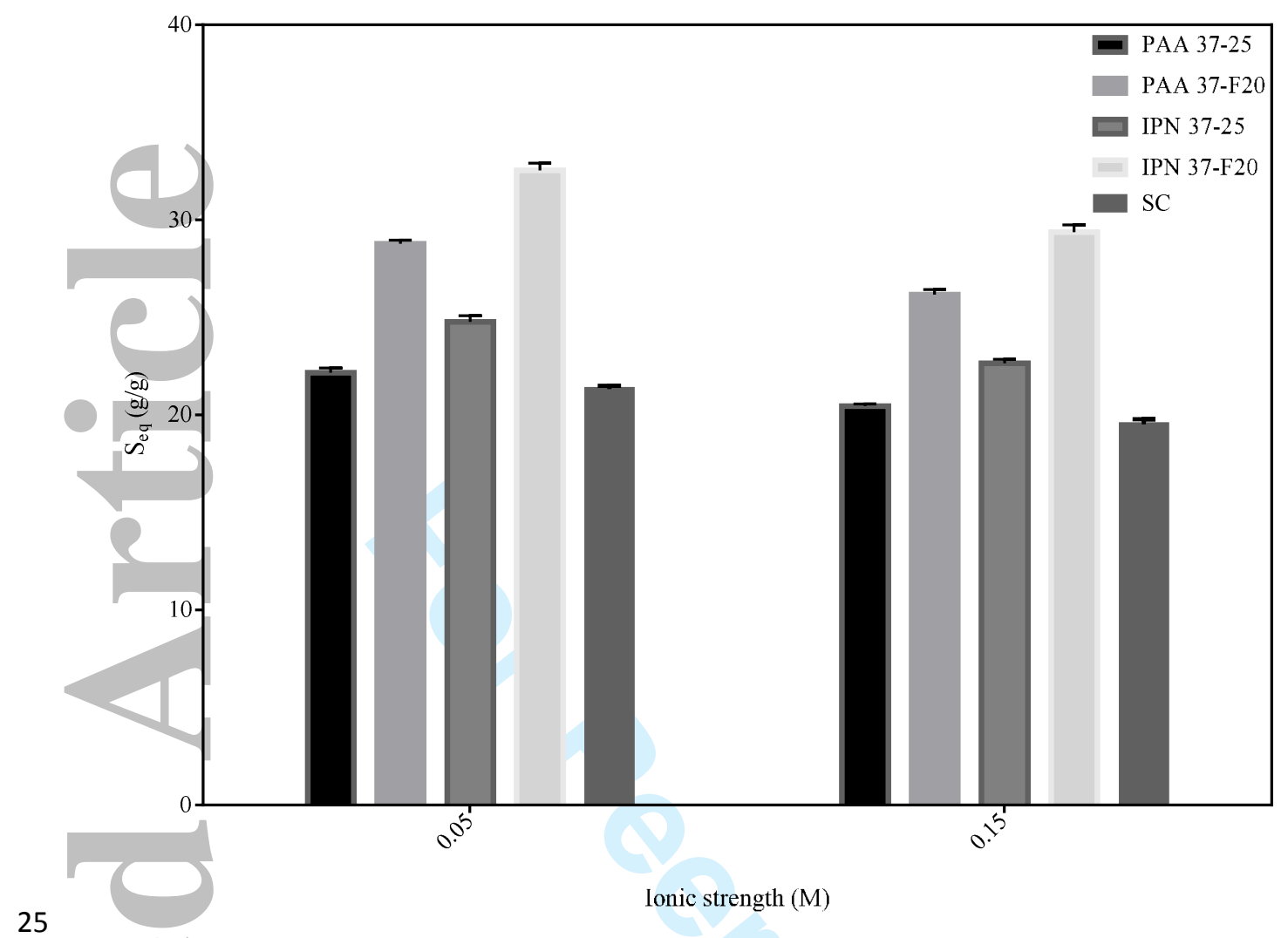
4

26 Figure 8. $\mathrm{S}_{\mathrm{eq}}$ of the hydrogels in PBS solution ( $\mathrm{pH}$ 7.4) prepared at different ionic strength.

27

28
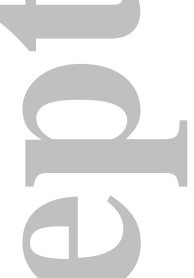

P

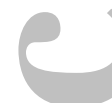

4

John Wiley \& Sons, Inc.

This article is protected by copyright. All rights reserved. 


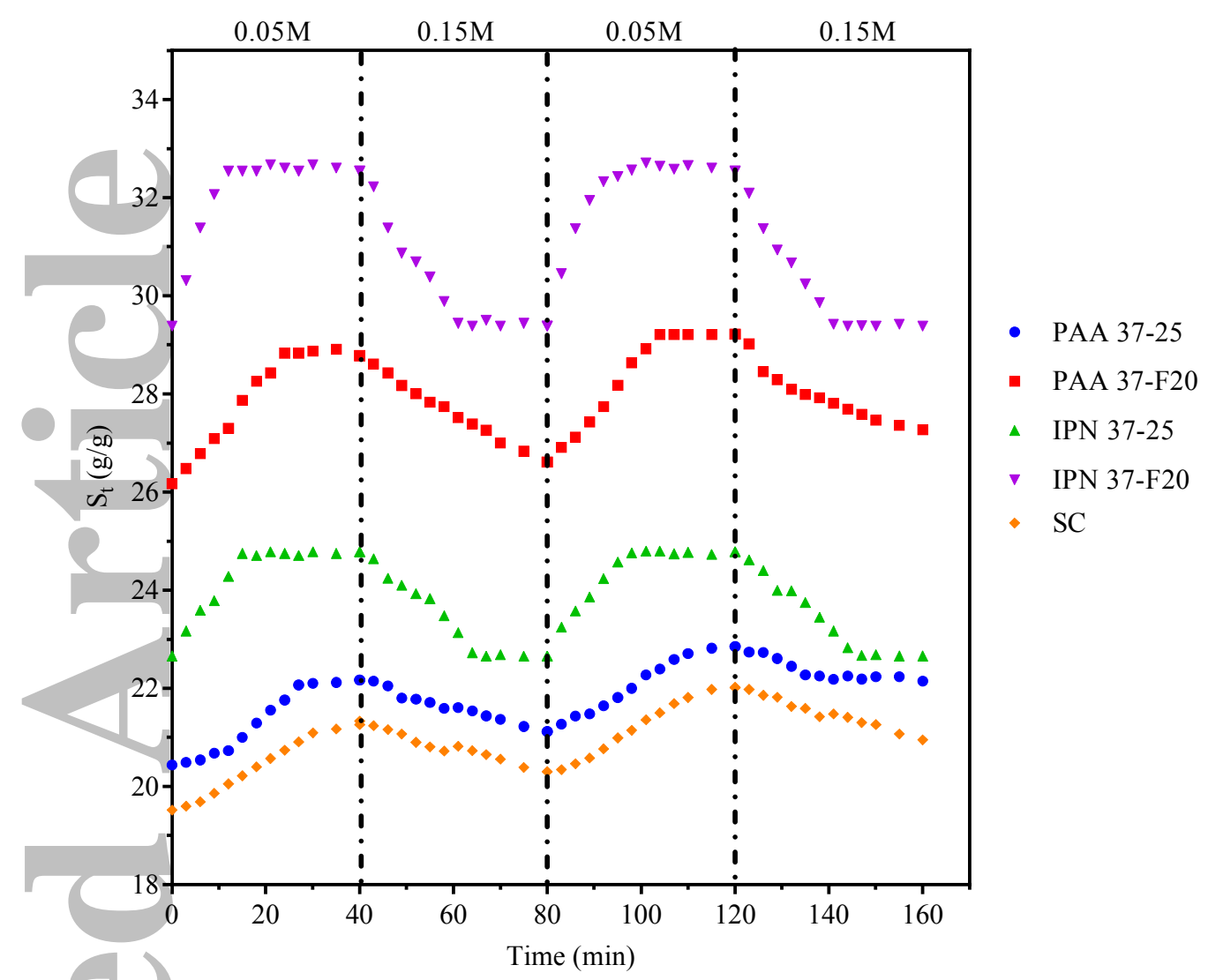

Figure 9. Time-dependent ionic-strength response of PAAc and semi-IPN PAAc/PASP hydrogels incubated in PBS solution at $\mathrm{pH}$ 7.4. The ionic strength of PBS solution was cycled between $0.05 \mathrm{M}$ and $0.15 \mathrm{M}$ every $40 \mathrm{~min}$ for a total of $160 \mathrm{~min}$.

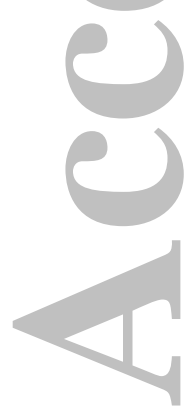

John Wiley \& Sons, Inc.

This article is protected by copyright. All rights reserved. 


\section{TABLES}

Table 1. Feed composition and polymerization conditions for the preparation of PAAc and semi-IPN PAAc/PASP hydrogels.

\begin{tabular}{|c|c|c|c|c|c|c|c|c|c|}
\hline \multirow[t]{2}{*}{ Sample code } & \multirow[t]{2}{*}{$\begin{array}{l}\text { AAc } \\
(\mathrm{mmol})\end{array}$} & \multirow[t]{2}{*}{$\begin{array}{l}\text { PASP } \\
\text { (mmol) }\end{array}$} & \multirow[t]{2}{*}{$\begin{array}{l}\text { APS } \\
(\mathrm{mg})\end{array}$} & \multirow[t]{2}{*}{$\begin{array}{l}\text { MBA } \\
\text { (mg) }\end{array}$} & \multirow[t]{2}{*}{$\begin{array}{l}\text { TEMED } \\
(\mu \mathrm{L})\end{array}$} & \multicolumn{2}{|c|}{$\begin{array}{l}\text { First-step } \\
\text { polymerization }\end{array}$} & \multicolumn{2}{|c|}{$\begin{array}{l}\text { Second-step } \\
\text { polymerization }\end{array}$} \\
\hline & & & & & & $\begin{array}{l}T \\
\left({ }^{\circ} \mathrm{C}\right)\end{array}$ & $\begin{array}{l}\text { Time } \\
(\min )\end{array}$ & $\begin{array}{l}T \\
\left({ }^{\circ} \mathrm{C}\right)\end{array}$ & $\begin{array}{l}\text { Time } \\
\text { (hours) }\end{array}$ \\
\hline 25 & 1 & 0 & 2 & 1 & 40 & 37 & 15 & 25 & 24 \\
\hline PAA 37-F20 & 1 & 0 & 2 & 1 & 40 & 37 & 15 & -20 & 24 \\
\hline IPN 37-25 & 1 & 0.01 & 2 & 1 & 40 & 37 & 15 & 25 & 24 \\
\hline IPN 37-F20 & 1 & 0.01 & 2 & 1 & 40 & 37 & 15 & -20 & 24 \\
\hline SC & 1 & 0 & 2 & 1 & 40 & 25 & 15 & 25 & 24 \\
\hline
\end{tabular}

Remark: 1) AAc, PASP, APS, MBA and TEMED were dissolved into $700 \mu \mathrm{L}$ of PBS. 2) The synthesized hydrogels were denoted based on the type of hydrogel formed as well as the reaction temperature of the first- and second-step polymerizations. In sample code, the letters "PAA" and "IPN" refer to PAAc hydrogel and semi-IPN PAAc/PASP hydrogel, respectively. The PAAc hydrogel prepared via the conventional method was denoted as "SC".

John Wiley \& Sons, Inc.

This article is protected by copyright. All rights reserved. 
Table 2. Swelling kinetics parameters of the hydrogels.

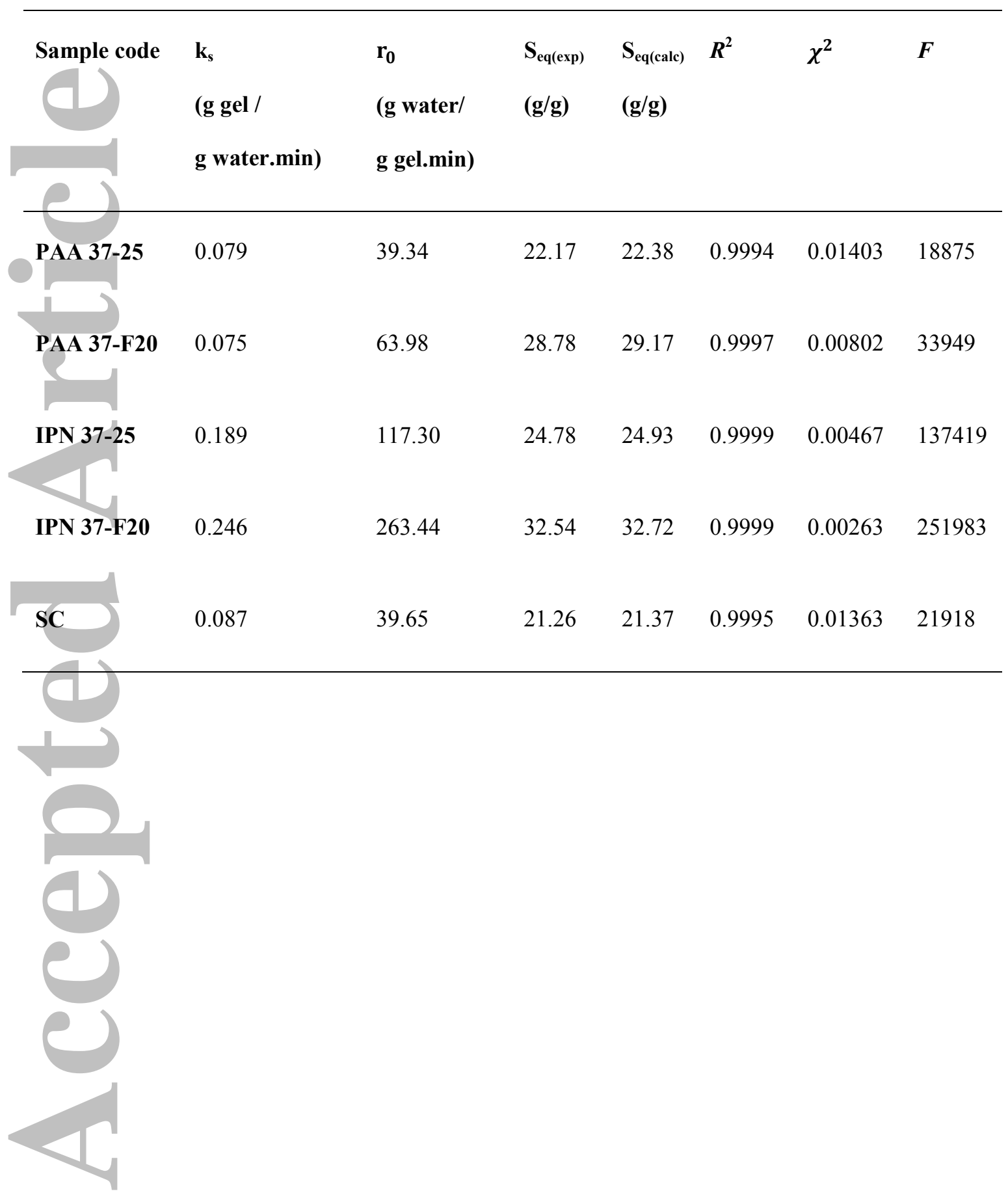

John Wiley \& Sons, Inc.

This article is protected by copyright. All rights reserved. 


\section{Supporting Information}

\section{Rapid swelling and deswelling of semi-interpenetrating network poly(acrylic acid)/poly(aspartic acid) hydrogel prepared by freezing \\ polymerization}

Swee Lu Lim ${ }^{a}$, Willie Ngee Hon Tang ${ }^{b}$, Chien Wei Ooi ${ }^{a, c}$, Eng-Seng Chan ${ }^{a, c}$, Beng Ti Tey ${ }^{a, c^{*}}$

${ }^{a}$ Chemical Engineering Discipline, School of Engineering, Monash University Malaysia, Jalan Lagoon Selatan, Bandar Sunway 47500, Selangor, Malaysia.

${ }^{b}$ Department of Chemical and Biomolecular Engineering, The University of Melbourne, Victoria 3010, Australia.

c Advanced Engineering Platform, Monash University Malaysia, Jalan Lagoon Selatan, Bandar Sunway 47500, Selangor, Malaysia.

Corresponding author: Beng Ti Tey (tey.beng.ti@monash.edu)

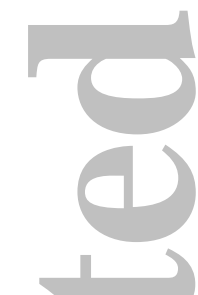

Confirmation on the integrity of semi-IPN PAAc/PASP hydrogel

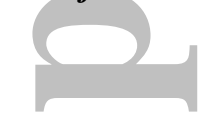

The integrity of the PAAc/PASP hydrogels was verified by identifying the sign of leakage of PASP from the hydrogel network. After the incubation of semi-IPN PAAc/PASP hydrogel in PBS solution for 7 days, the PBS solution (i.e., washing buffer) was sampled for the analysis of UV-Vis spectrophotometry (Agilent Technologies Cary 100, USA) to determine the amount of leaked PASP in the solution. Figure S1 shows the result of UV-Vis spectrophotometric analysis.

John Wiley \& Sons, Inc.

This article is protected by copyright. All rights reserved. 


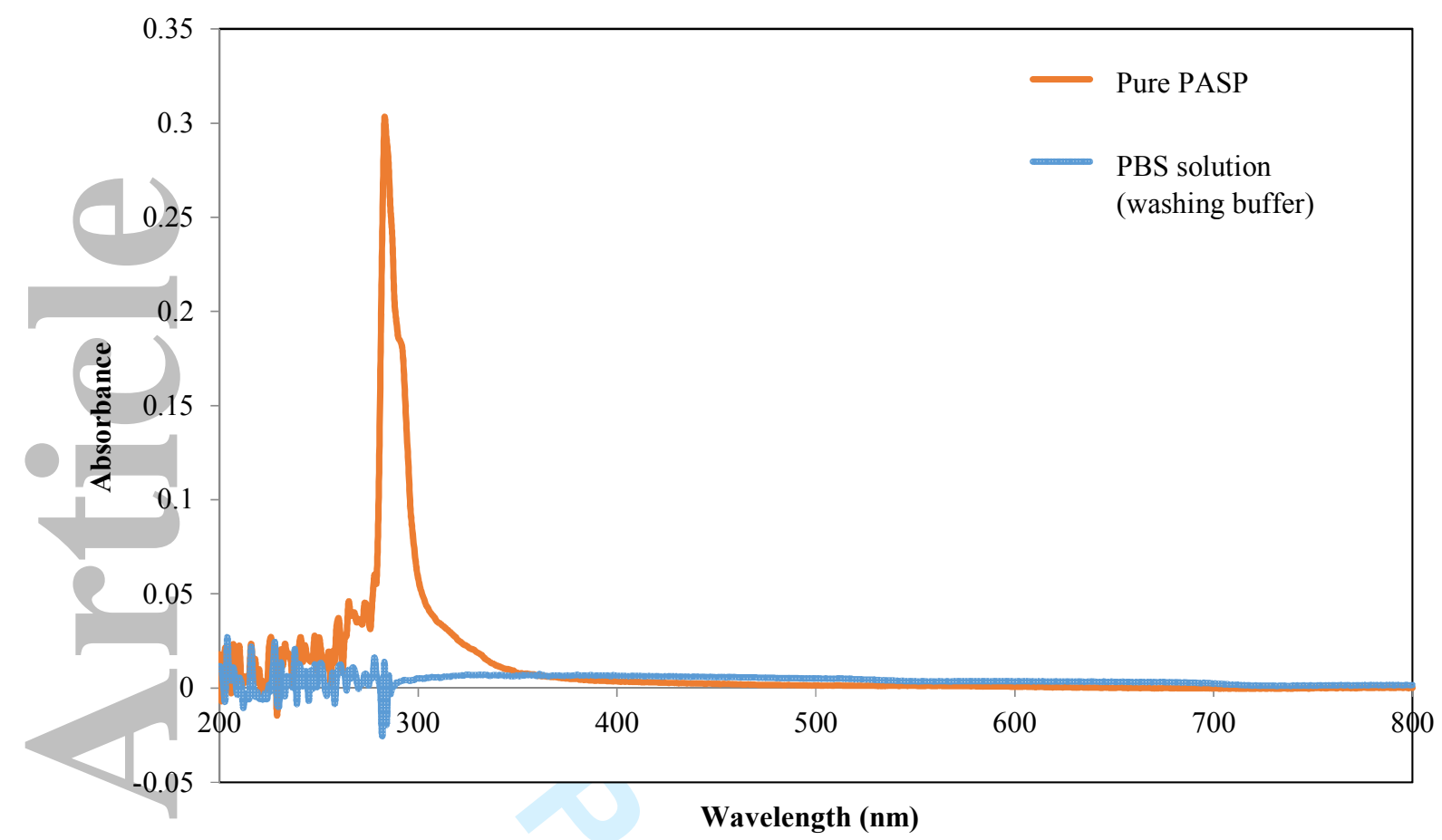

Figure S1. UV-Vis spectra of the pure PASP and the PBS solution (washing buffer).

A strong characteristic peak was appeared at $\sim 283 \mathrm{~nm}$ in the spectrum of pure PASP. In contrast, the spectrum of sample solution did not contain a peak at $283 \mathrm{~nm}$, thus confirming that the PASP did not leak out from the hydrogel network.

John Wiley \& Sons, Inc. 
Manuscript ID: APP-2015-08-2876.R1

\section{Responses to reviewers}

We thank the reviewer for their detailed comments on the paper. Our responses are detailed below.

\begin{tabular}{|c|c|c|}
\hline Comments & Responses & Remarks \\
\hline \multicolumn{3}{|l|}{ Reviewer 3} \\
\hline $\begin{array}{l}\text { Line 109-111, The authors showed } \\
\text { the result that the PASP did not leak } \\
\text { out from the hydrogel network. } \\
\text { Please add some comment about this } \\
\text { fact in the manuscript, since the } \\
\text { readers do not need to worry about it. }\end{array}$ & $\begin{array}{l}\text { We have elaborated the results of } \\
\text { integrity of semi-IPN PAAc/PASP } \\
\text { hydrogel in the Supporting } \\
\text { Information. } \\
\text { "No sign of leakage was observed for } \\
\text { the synthesized semi-IPN PAAc/PASP } \\
\text { hydrogel (see } \quad \text { Supporting } \\
\text { Information)." }\end{array}$ & $\begin{array}{lr}\text { Page } & 5, \\
\text { lines } & 110- \\
111 & \end{array}$ \\
\hline $\begin{array}{l}\text { Line 184-188, "The strong } \\
\text { electrostatic repulsion force PAAc } \\
\text { and PASP carboxylate anions (- } \\
\text { COO-) created the voidage between } \\
\text { the PAAc and PASP polymer chains, } \\
\text { forming a porous structure during the } \\
\text { polymerization process } 31 \text {." This } \\
\text { explanation is not acceptable. The } \\
\text { void, that is, the inhomogeneity, in } \\
\text { the hydrogel is caused by the } \\
\text { polymer network concentration } \\
\text { difference, which is fixed by the } \\
\text { crosslinking. In this sense, the void } \\
\text { is produced by the formation of the } \\
\text { domain different in the concentration } \\
\text { of polymer chain followed by the } \\
\text { crosslinking to form the polymer } \\
\text { network having the void, that is, } \\
\text { inhomogeneity. } \\
\text { electrostatic repulsion is the origin of } \\
\text { the void formation, which is the } \\
\text { author's explanation, the void will } \\
\text { arise even in the solution of linear } \\
\text { ionic polymer chains. This cannot be } \\
\text { reasonably acceptable. Generally, the } \\
\text { origin of the void formation in the } \\
\text { polymer network is due to the phase } \\
\text { separation of the polymer chain }\end{array}$ & $\begin{array}{l}\text { We thank the reviewer for the } \\
\text { comment. We agree with the } \\
\text { explanation, hence an amendment has } \\
\text { been made in the manuscript. } \\
\text { "The presence of void or } \\
\text { inhomogeneity in the hydrogel was } \\
\text { caused by the micro-phase separation } \\
\text { between AAc monomers and PASP } \\
\text { polymer chains, thereby creating the } \\
\text { domain difference followed by the } \\
\text { crosslinking to form the polymer } \\
\text { network." }\end{array}$ & $\begin{array}{lr}\text { Page } & 9, \\
\text { lines } & 182- \\
183 & \end{array}$ \\
\hline
\end{tabular}




\begin{tabular}{|l|l|l|}
\hline followed by the crosslinking to form \\
the inhomogeneity. In this study, fine \\
piece of ice formation as well as the \\
phase separation of PAAc and PASP \\
may produce the domains different in \\
the concentration of the polymer \\
chains followed by the crosslinking \\
to form the void.
\end{tabular}
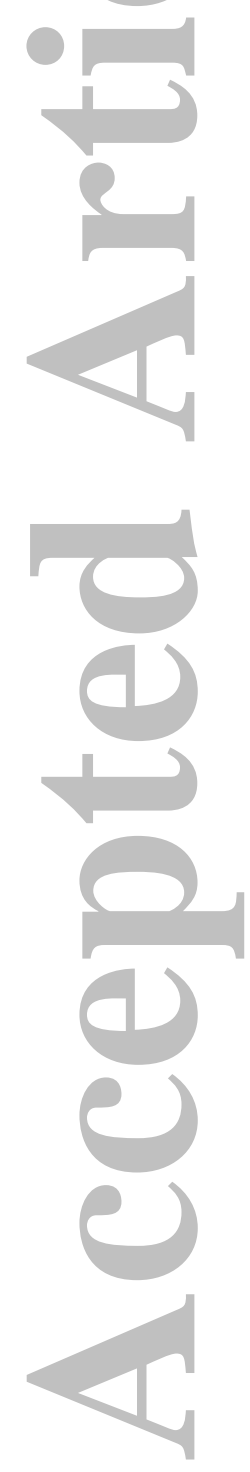

John Wiley \& Sons, Inc.

This article is protected by copyright. All rights reserved. 


\section{University Library}

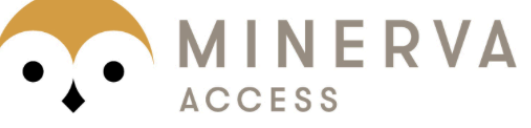

A gateway to Melbourne's research publications

Minerva Access is the Institutional Repository of The University of Melbourne

Author/s:

Lim, SL;Tang, WNH;Ooi, CW;Chan, E-S;Tey, BT

Title:

Rapid swelling and deswelling of semi-interpenetrating network poly(acrylic acid)/ poly(aspartic acid) hydrogels prepared by freezing polymerization

Date:

2016-06-20

Citation:

Lim, S. L., Tang, W. N. H., Ooi, C. W., Chan, E. -S. \& Tey, B. T. (2016). Rapid swelling and deswelling of semi-interpenetrating network poly(acrylic acid)/poly(aspartic acid) hydrogels prepared by freezing polymerization. JOURNAL OF APPLIED POLYMER SCIENCE, 133 (24), https://doi.org/10.1002/app.43515.

Persistent Link:

http://hdl.handle.net/11343/291025 